\title{
Determination of Antioxidant Compounds in Foodstuff
}

\author{
Amilcar L. Antonio, Eliana Pereira, José Pinela, Sandrina Heleno, \\ Carla Pereira and Isabel C.F.R. Ferreira*
}

Mountain Research Centre (CIMO), ESA, Polytechnic Institute of Bragança, Bragança, Portugal

\begin{abstract}
Phenolic compounds, vitamins and carotenoids are naturally found in different foodstuff. These antioxidant compounds play an important role in human health and are of interest for the food, pharmaceutical and cosmeceutical industries. Modern chromatographic and spectrometric techniques have made analysis easier than ever before, but their success depends on the extraction method used. In fact, the different antioxidants are identified using chromatographic techniques coupled to different specific detectors according to the characteristics of each molecule. Beyond their well-known health-promoting effects, antioxidant molecules can also be used to functionalize or preserve the freshness, nutritive value, flavor and color of foodstuffs, which justify their incorporation into several matrices. In this chapter, the most common antioxidant compounds in foodstuff will be described, as well as the methodologies involved in their extraction, separation, identification and quantification. The bioactive properties and industrial applications of these compounds through innovative techniques will also be taken into account.
\end{abstract}

Keywords: Antioxidants, natural sources, extraction, identification, quantification, structure elucidation

\subsection{Introduction}

Free radicals and their reactive metabolites, named as reactive oxygen and nitrogen species (ROS and RNS, respectively), are produced in the natural

${ }^{*}$ Corresponding author: iferreira@ipb.pt

Umile Gianfranco Spizzirri and Giuseppe Cirillo (eds.) Food Safety: Innovative Analytical Tools for Safety Assessment, (179-220) @ 2017 Scrivener Publishing LLC 
metabolism of aerobic cells, being generated from endogenous (metabolic processes, electron transport chain and the nitric oxide synthase reaction) and exogenous (pollution, radiation, chemical exposure, smoking, etc.) sources [1]. Ideally, these compounds are posteriorly eliminated by cellular and tissue defenses, but this equilibrium can be compromised by the excessive production of reactive metabolites creating an oxidative stress that can lead to several damages of important biomolecules and organs with potential impact on the whole organism [1]. The complex human antioxidant defense system includes endogenous and exogenous antioxidant defenses that must maintain the cellular redox homeostasis, minimizing the levels of reactive species while allowing appropriate ROS-mediated biological signaling [2]. This system includes endogenous antioxidant enzymes such as superoxide dismutase, catalase and glutathione peroxidase that catabolize superoxide radicals and degrade hydrogen peroxide and hydroperoxides, respectively; proteins like albumin, transportation proteins for iron ions, transferrin and various metallothioneins; and low molecular-weight scavengers such as thioredoxin, $\alpha$-tocopherol, ascorbate, uric acid, coenzyme Q, and lipoic acid [3-5]. Beyond these endogenous defenses, exogenous antioxidants supplied by dietary sources can support the prevention of oxidative damage, which explains the several changes observed in eating habits. Indeed, the practice of a correct and balanced diet using functional foods has been recruiting more and more followers and numerous scientific studies have been performed not only on chemical and nutritional properties of foods, but also on the evaluation of their health benefits [6]. Many functional foods have antioxidants in their composition and, in addition to their basic nutritional function, these foods also help to reduce the risk of cancer, osteoporosis and hypertension, improve gastrointestinal and bone health, delay the aging process, enhance the immune system, improve depressive states and the quality of sleep, increase energy levels and improve performance of athletes $[7,8]$.

In this chapter, the most common antioxidants present in food and their industrial applications will be presented, along with a comparison between conventional and emerging extraction methodologies of antioxidants, and the most suitable identification and isolation techniques.

\subsection{Common Antioxidants in Foodstuff}

The antioxidant molecules present in food are able to directly eliminate ROS, act in the regulation of antioxidant defenses, and inhibit the production of these species. Furthermore, these compounds have the ability to 
form new radicals that are stable through intramolecular hydrogen bonding on further oxidation, after radical scavenging [6,9].

Some examples are vitamins (A, B, C, D, E and K), carotenoids (lycopene, $\beta$-carotene and xanthophylls) and polyphenols (flavonoids such as flavonols, flavones, flavanones, flavanols (flavan-3-ols), anthocyanins, and isoflavones, phenolic alcohols, phenolic acids, tannins, stilbenes and lignans) [10]. There are several foods that contain these molecules in their composition, particularly fruits, vegetables, spices, herbs, mushrooms, fish, milk products, among others (Table 6.1). This agro-food group highlights the spices and herbs as major carriers of antioxidants.

Table 6.1 includes information about the main classes of compounds with antioxidant activity and their natural sources. Vitamins play an important role in human health, since they are a group of essential compounds for normal growth and functioning of the organism. However, since the body does not have the capacity to synthesize vitamins, it is possible to obtain these compounds from food or pharmaceutical products, which are generally converted into more complex molecules that act as co-enzymes when ingested. The incorrect ingesting of this micronutrient triggers harmful pathological reactions that compromise the normal development of the body [11]. Vitamins are divided into two groups, liposoluble vitamins (A, $\mathrm{D}, \mathrm{E}$ and $\mathrm{K}$ ) and hydrosoluble vitamins (B and C) [12]. The sources of these two groups are different, as well as their chemical behavior. The liposoluble vitamins have a chemical structure similar to some lipids (steroids) and are easily stored by the body. However, the process is energetically expensive, since it requires the synthesis of fat reserves, and their elimination is also more complex. Differently, water-soluble vitamins are more difficult to be stored, requiring constant replacement and are also easily eliminated by the organism, preventing excessive quantities of these vitamins. Almost all the vitamins of this type are essential enzymes or coenzymes $[12,13]$.

Other antioxidant molecules are the carotenoids that are natural pigments responsible for the yellow, orange and red color present in various foods which display a variety of functions in nature, especially in animal diet, since they act in deactivating a wide variety of reactive radicals in biological systems [14].

The natural functions of carotenoids are principally determined by their molecular properties such as size, geometry, presence of functional groups and other characteristics [15]. These molecules can be found in plants and microorganisms. In nature there are over 600 carotenoids, which are classified as carotenes, xanthophylls and lycopene [14]. $\beta$-Carotene is an abundant micronutrient, which can be found in many vegetables and fruits. Due to its water-insolubility, this molecule's absorption process is 
182 Food Safety: Innovative Analytical Tools

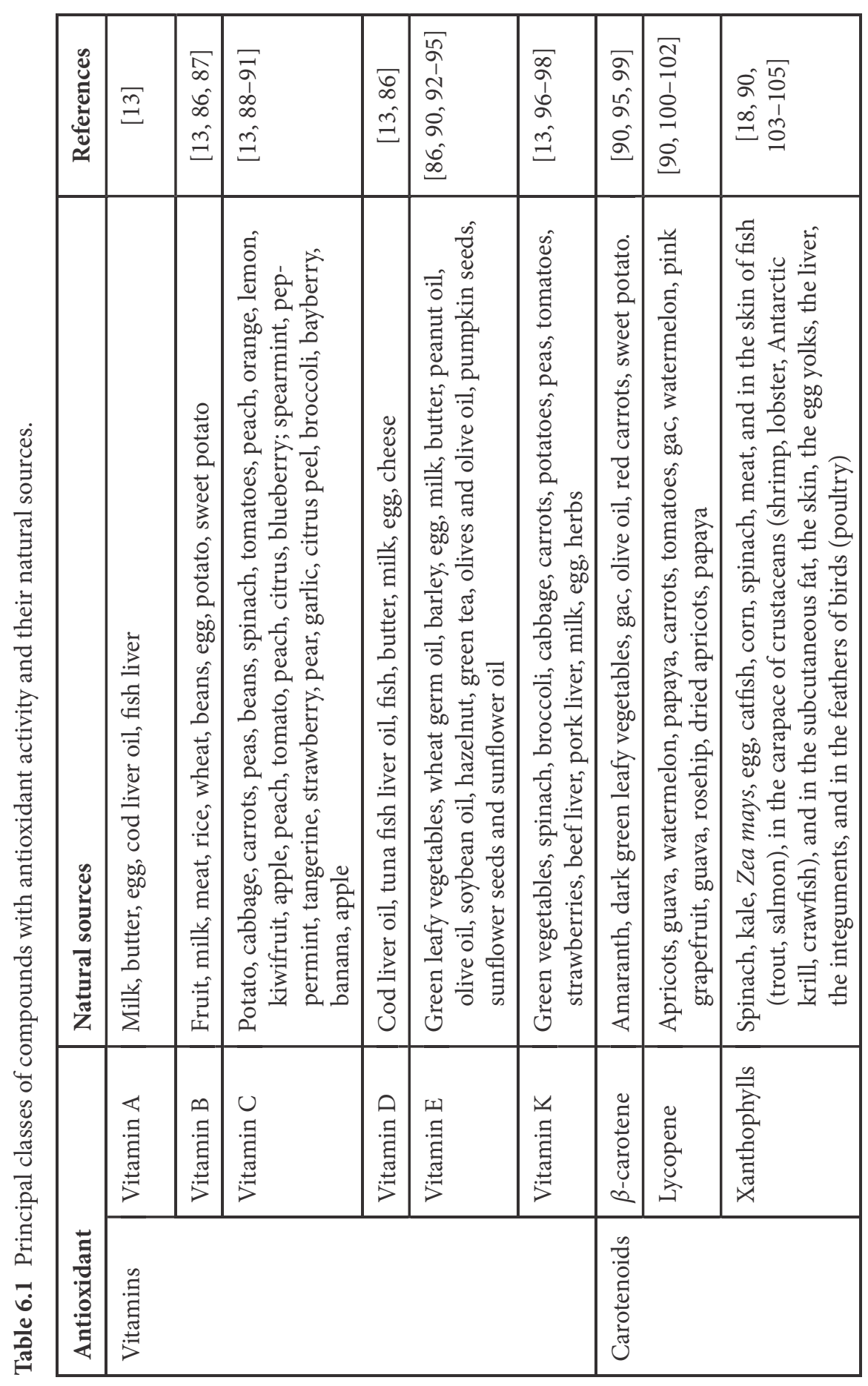




\begin{tabular}{|c|c|c|c|c|}
\hline 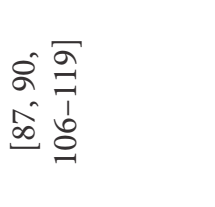 & 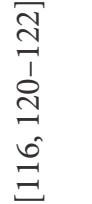 & 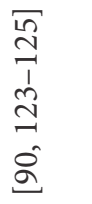 & 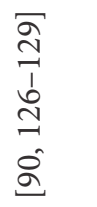 & 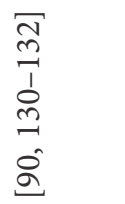 \\
\hline 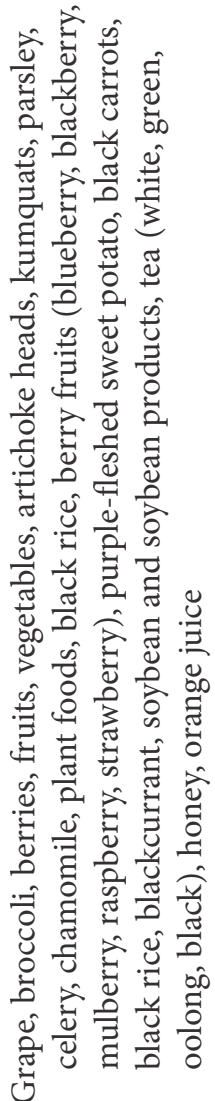 & 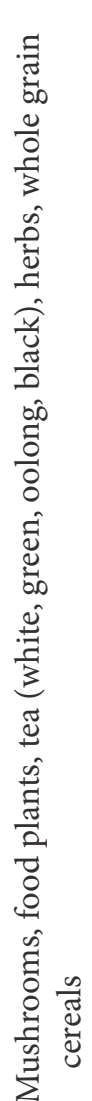 & 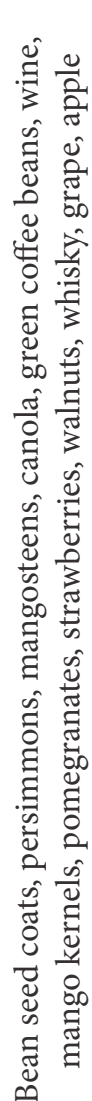 & 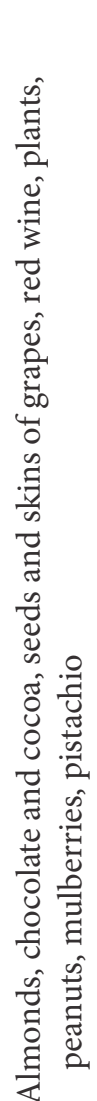 & 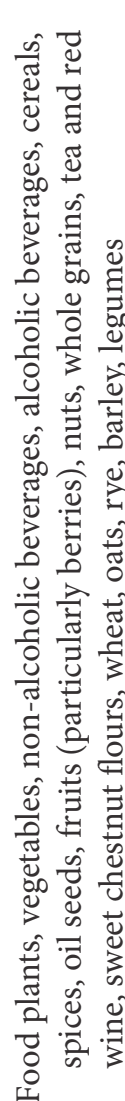 \\
\hline 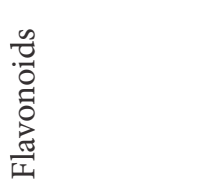 & 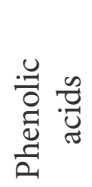 & 蔦 & 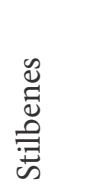 & 苂 \\
\hline \multicolumn{5}{|l|}{ 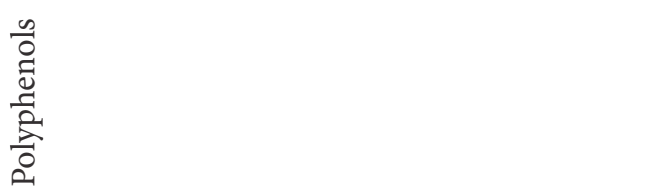 } \\
\hline
\end{tabular}


passive and parallels that of lipids. Another characteristic of $\beta$-carotene is its degradation by exposure to light, heat, and oxygen, which can be converted in a pro-oxidant, causing a negative effect on human health [16]. Another micronutrient belonging to the class of carotenoids is lycopene. This is the most abundant carotenoid and the compound responsible for the red color of various foods (such as tomatoes and tomato products) and is known for its oil solubility and sensitivity to light and heat. It deteriorates easily during processing and storage, and presents low bioavailability. Regarding the conducted studies, this compound beneficially intervenes in health, acting in the prevention of cancer and cardiovascular diseases [17]. The xanthophylls are also carotenoids, and their wide distribution in the different phylogenetic kingdoms and their broad structural variety, allow multiple functions of these organic molecules in living organisms. It has been demonstrated that the ingestion of this molecule helps in preventing macular degeneration associated with age and the development of cataracts. Therapeutically, it also acts in reducing the risk of developing several types of cancer [18-20].

Finally, another class of molecules with bioactive potential are the polyphenols, which include a large group of biologically active compounds (flavonoids, phenolic acids, tannins, stilbenes and lignans). The interest in these compounds has been gradually increasing ever since performed scientific studies have associated polyphenols with the decrease in the risk of several diseases related to oxidative stress [21, 22]. Thus, their antioxidant potential has been associated with different therapeutic actions, including anticarcinogenic/antimutagenic, antibacterial, antiviral and anti-inflammatory [23]. As in the previously mentioned compounds, the antioxidant activity of these molecules is also influenced by its structure, in particular by the required number and position of phenolic hydroxyl and other chemical features.

\subsection{Antioxidants for Bioactive or Preservative Purposes}

Antioxidants may be classified as natural or synthetic, with the former arising naturally in the food composition, as described above. Otherwise, synthetic antioxidants have been developed for the purpose of incorporation into food in order to make them resistant to various treatments and conditions, prolonging the shelf life. The principal and most available antioxidants in the food industry are BHA, BHT, PG and TBHQ [24]. BHT (butylated hydroxytoluene) and BHA (butylated hydroxyanisole) are the 
most widely used chemical antioxidants and have shown similar properties. During the period from 2011 to 2012, the European Food Safety Authority (EFSA) reevaluated all the available information about these two antioxidants, including apparently contradictory information that had been published. EFSA established revised acceptable daily intakes (ADIs) of $0.25 \mathrm{mg} / \mathrm{kg}$ bw/day for BHT and $1.0 \mathrm{mg} / \mathrm{kg}$ bw/day for BHA and noted that the exposure of adults and children to these antioxidants was unlikely to exceed these intakes $[10,25,26]$. PG (propyl gallate) has a great concentration of activity as an antioxidant and when used at high levels it assumes a pro-oxidant role. The TBHQ (terc-butyl-hydroquinone) is used to stabilize and preserve freshness, nutritional value, taste and color of food products of animal origin [10,27].

In fact, these synthetic antioxidants are effective and cheaper than natural antioxidants, which explains their wide use in the food industry; notwithstanding, the demand for natural food additives over synthetic ones has been growing in an attempt to avoid the possible chemically induced carcinogenic effects [28]. Moreover, the synergism observed between various natural antioxidants present in food extracts is an advantage that cannot be achieved with an isolated synthetic antioxidant [29]. In this field, and taking into account that lipid peroxidation is the second major cause, after microbial spoilage, of decline of food nutritional and sensory quality traits [30], several studies have been performed in order to test the antioxidant capacity of natural antioxidants when introduced into foodstuff. This research focused essentially on animal origin products because of their specific constitution. For example, the presence of residual blood in meat products equates to retention of more haemoglobin, which is a powerful promoter of lipid oxidation and further rancidity, especially under oxidative conditions such as storage and cooking $[31,32]$. On the other hand, fish products richness in n-3 polyunsaturated fatty acids (PUFA) makes them susceptible targets to peroxidation that leads to rancid taste and off flavor, limiting their time of storage and processing possibilities [33]. Thus, several extracts of plants have been introduced into these matrices and proved to possess preservative effects by limiting their oxidation (Table 6.2). As a great example, when widely employed in meat and meat products, rosemary extracts are able to decrease thiobarbituric acid reactive substances (TBARS), hexanal quantities and protein oxidation in cooked pork patties and beef burgers [34-37]. Furthermore, combinations of extracts from rosemary, marjoram, and sage significantly decreased the lipid oxidation of ground beef [38], while oleoresin of rosemary reduced TBARS and hexanal in raw ground beef and cooked patties [39]. Moreover, these plant extracts were also tested in fish muscle, namely sea salmon, and produced 
186 Food Safety: Innovative Analytical Tools

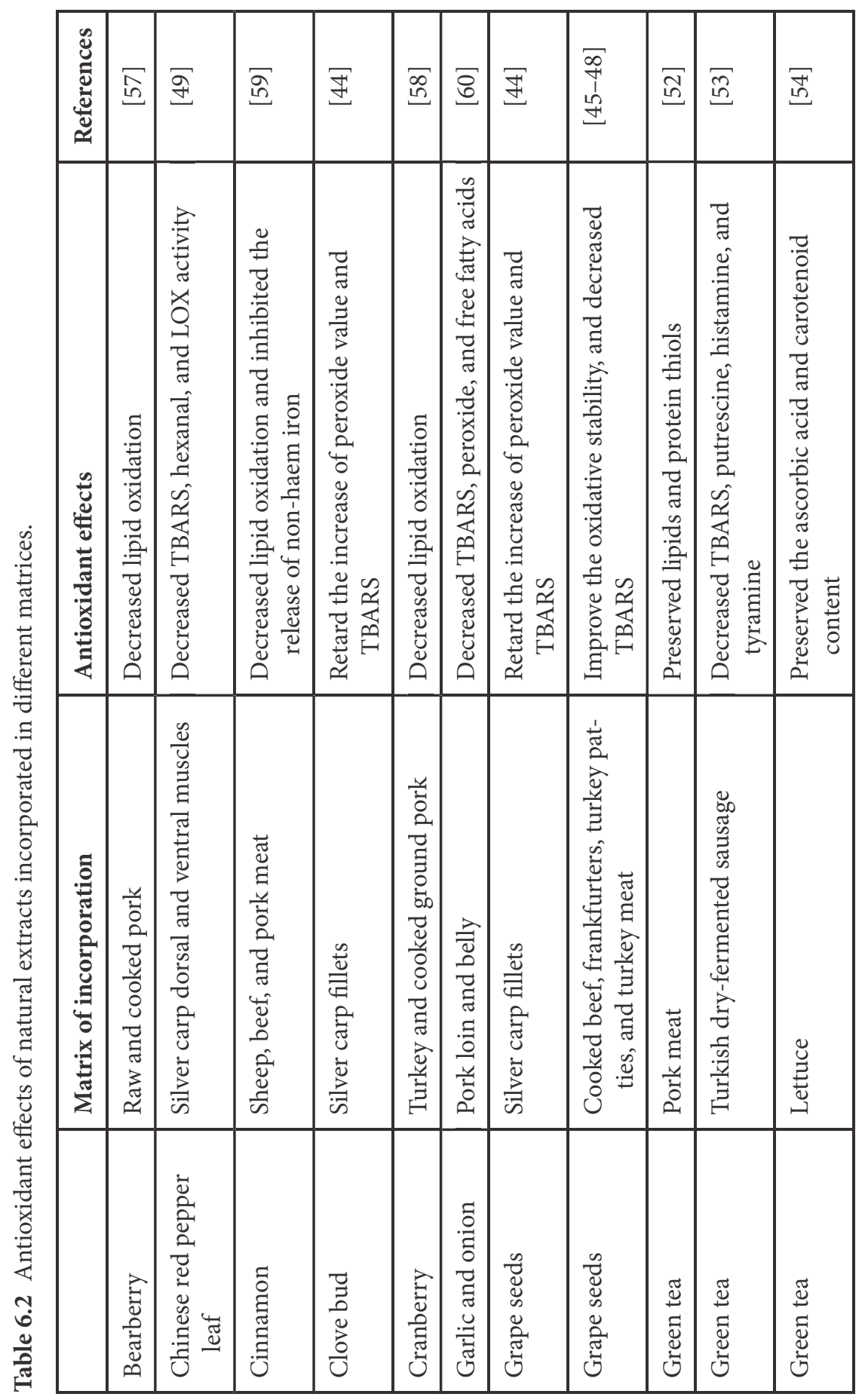




\begin{tabular}{|c|c|c|c|c|c|c|c|c|c|}
\hline$\underline{n}$ & in & $\hat{m}$ & $\overrightarrow{6}$ & $\begin{array}{l}\bar{\alpha} \\
\infty \\
\dot{1} \\
\infty\end{array}$ & 焉 & $\exists$ & $\stackrel{\infty}{=}$ & $\mid$\begin{tabular}{|l}
$n$ \\
$n$ \\
$n$
\end{tabular} & in \\
\hline 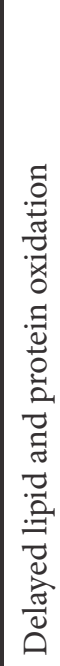 & 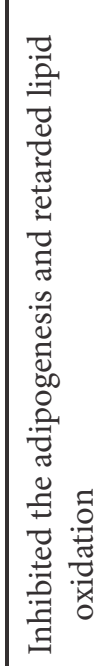 & 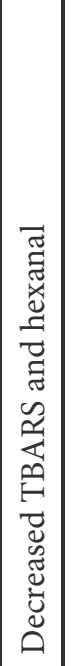 & 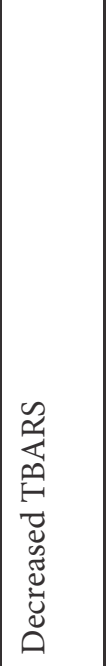 & 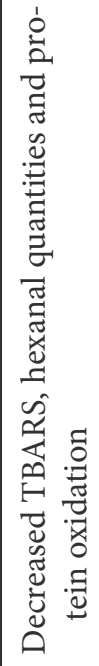 & 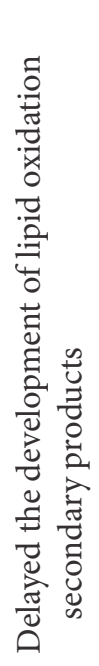 & 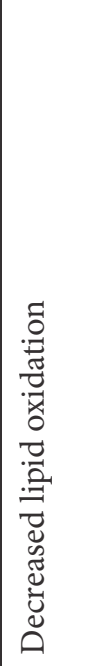 & 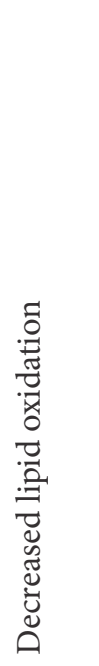 & 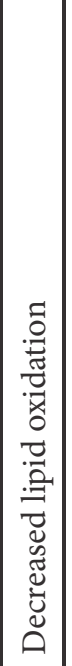 & 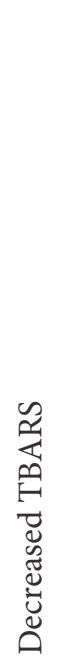 \\
\hline 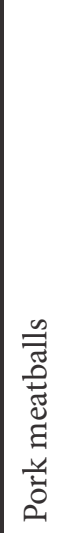 & 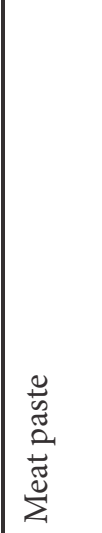 & 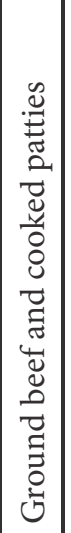 & 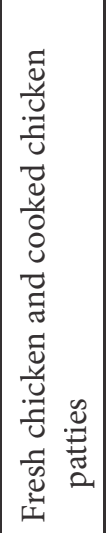 & 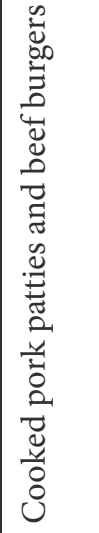 & 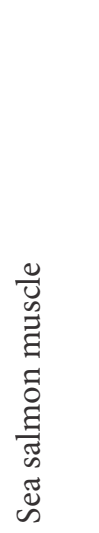 & 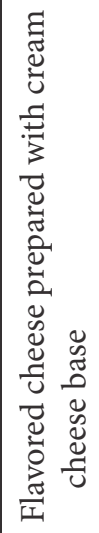 & 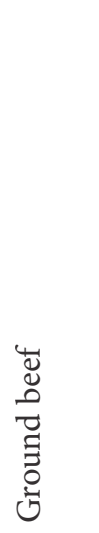 & 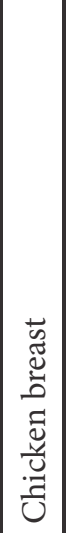 & 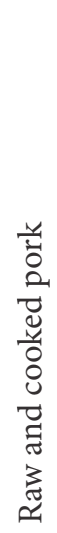 \\
\hline 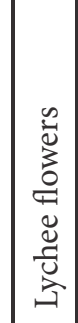 & 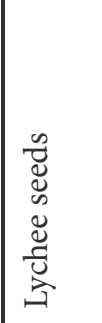 & 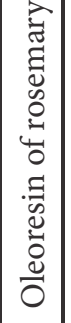 & 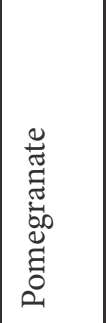 & 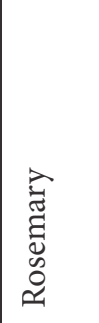 & 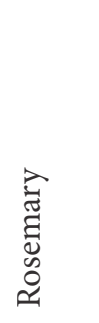 & 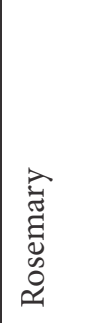 & 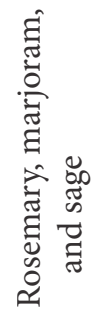 & $\left|\begin{array}{c}0 \\
\infty \\
\tilde{n} \\
\tilde{n}\end{array}\right|$ & 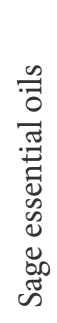 \\
\hline
\end{tabular}


a delay in the development of lipid oxidation secondary products [40], and revealed the capacity to prolong the shelf life of flavored cheese prepared with cream cheese base by preventing lipid oxidation [41]. Indeed, in 2010 the European Union authorized the use of rosemary extracts as new food additives for use in foodstuffs under Directive 95/2/EC and assigned it the E 392 number $[42,43]$.

Nonetheless, there are several other examples of plants with similar antioxidant effects in meat and/or fish products. For example, extracts of clove bud and grape seeds have been used to retard the increase of peroxide value and TBARS of silver carp fillets during chilled storage [44], and were also later revealed to improve the oxidative stability of cooked beef [45], frankfurters [46], turkey patties [47], and turkey meat stored cold, especially in air, but also under vacuum [48]. Chinese red pepper leaf extracts were able to decrease the hexanal contents, the TBARS values and the lipoxygenase (LOX) activity in salted silver carp dorsal and ventral muscles during processing [49], while water extracts of lychee seeds were added to meat paste to inhibit the adipogenesis and retard lipid oxidation [50]; and lychee flower delayed lipid and protein oxidation of emulsified pork meatballs [51]. In turn, green tea extracts preserved both lipids and protein thiols of pork meat emulsion without jeopardizing the oxidative stability or the physicochemical properties of the meat proteins [52]. Moreover, these extracts significantly reduced TBARS, putrescine, histamine, and tyramine formation in Turkish dry-fermented sausage [53], and preserved the ascorbic acid and carotenoid content of minimally processed lettuce [54]. Mariutti et al. [55] reported the positive effects (control of lipid oxidation) of sage extracts in minced chicken breast, and Fasseas et al. [56] observed decreased TBARS formation in raw and cooked pork in the presence of sage essential oils. Moreover, bearberry extracts were found to exhibit potent lipid antioxidant activity in raw and cooked pork [57], whereas crude cranberry extract inhibited the oxidation in mechanically separated turkey and cooked ground pork, but its polyphenolic fraction revealed even higher inhibition of hemoglobin-mediated lipid oxidation than the extract itself [58]. Cinnamon extracts controlled warmed-over flavor, lipid oxidation, and inhibited the release of non-haem iron in sheep, beef and pork meat [59]. The addition of garlic and onion powder to pork loin and belly increased yellowness and reduced the free fatty acids, peroxide, and the TBARS values [60]; and pomegranate rind powder reduced TBARS values in fresh chicken, and then in prepared cooked chicken patties [61]. Beyond these studies, many other extracts were tested, as well as combinations of different plants extracts, and even combinations of natural and synthetic antioxidants. 
Nevertheless, the direct use or incorporation of free bioactives in foodstuff (either as extracts, fractions of extracts, or isolated compounds) has several considerable limitations related to the loss and transformation of the antioxidant molecules, and to their interaction with other compounds. Moreover, the processing steps involved in the preparation of food matrices can influence the degradation or transformation of the antioxidant compounds due to factors such as endogenous enzymes action, water activity, oxygen pressure, and also thermal/mechanical energy [62].

In this connection, microencapsulation arises as a suitable option to stabilize the extracts to be incorporated into food; it can be defined as a process through which tiny particles or droplets are surrounded by a coating or embedded in homogeneous or heterogeneous matrices with the aim of producing small capsules with many useful properties [63]. This technique was first used in the early 1930s in order to coat some flavors and, then, ingredients such as antioxidants, preservatives, oxidation-reduction agents, enzymes, acids, bases, nutrients, crosslinking agents, buffers, flavors, sweeteners, and colors started to be produced worldwide on an industrial scale [64]. In the food industry, microencapsulation found its application in protecting the core material from adverse environmental conditions and enhancing the shelf life of products by controlling the release of the encapsulated materials [65]. Several studies have been performed in this field and there is a significant use of extracts, followed by polyphenols, essential oils, vitamins, proteins and fat extracts, applied to food. For instance, in regard to dairy products, microencapsulated isoflavones were added to milk and it was verified that an increased absorption in the intestine took place without affecting the taste [66]; phenolic extracts of pomegranate peels were incorporated into ice cream and proved to enhance antioxidant and $\alpha$-glucosidade inhibitory properties [67]; phenolic extracts from elm leaf blackberry flowers introduced into yogurt revealed a higher antioxidant activity than yogurt containing the extract in the free form [68]; and yogurt containing phenolic extracts from pomegranate fruits showed higher content of phenolic compounds and anthocyanins than the control [69]. On the other hand, microencapsulated aqueous extracts of wild strawberry applied in $k$-carrageenan gelatin revealed the ability to preserve the antioxidant properties when compared to the free form [70]. Also, cottage cheese enriched with mushrooms (Suillus luteus [L.: Fries] and Coprinopsis atramentaria [Bull.]) extracts revealed a clear tendency for higher antioxidant preservation over the time of storage when microencapsulated extracts were applied [71]. Regarding the citric acid and its derivative (-)-hydroxycitric, citric acid was incorporated into chewing 
gum to promote its health properties [72], whereas its derivative was added to bread [73, 74] and pasta [75], showing good sensory and quality attributes. Another application in bread was performed by Pasrija et al. [76] that introduced microencapsulated green tea polyphenols into this matrix to retain the quality characteristics along with its functionality. Moreover, a soup powder was enriched with linseed oil (rich in omega-3 fatty acids) to allow a controlled release of the lipophilic compounds [77], while cheese was enriched with vitamins E, A and CoQ10 [78] to inhibit lipid peroxidation (rancidity).

Beyond microencapsulation, the incorporation of bioactive extracts or isolated compounds into packaging films has been assessed in different studies $[79,85]$ and represents a new packaging concept of great interest to the food industry by allowing the preservation of food characteristics and the delay of oxidative processes. In some cases, the incorporation of antioxidants seems to be more efficient than the direct use of additives on meat surface, and thereby, some packaging systems have been developed with natural extracts (such as cocoa, rosemary, oregano, green tea, oolong tea, and black tea, among others) to increase the stability of meat products and extend their shelf life [79-83]. This technique was also applied to extend cheese shelf life [84] and was effective in salmon muscle, using natural antioxidant products containing tocopherols in the development of active packaging [85].

\subsection{Analysis of Antioxidants in Foods}

Nowadays, several methods are available for analysis of antioxidants. These methods involve the evaluation of total antioxidant activity and the individual identification and quantification of different antioxidant compounds. Modern chromatographic and spectrometric techniques have made antioxidant compound analysis easier than ever before, but their success depends on previous treatments and extraction steps.

\subsubsection{Extraction of Antioxidant Compounds}

Extraction is a very important analytical step in the isolation and identification of compounds from different foodstuffs prior to chromatographic determination. The development of optimal procedures can prove difficult due to the structural diversity of the compounds and their potent antioxidant activity, which can lead to rapid reaction with other constituents in the matrix [133]. Therefore, the quality of extracts obtained from 
different foodstuffs is strongly related to the employed extraction method [134]. Thus, appropriated extraction techniques and conditions should be adopted, taking into account the compound to be extracted and the accurate nature of matrix to be studied. This involves using conventional extraction methods or innovative technologies (Figure 6.1), including ultrasounds, microwaves, pulsed electric fields, high voltage electrical discharges, pressurized or supercritical fluids, and enzymes, or combinations of these techniques. The basic mechanisms and recent practical examples are discussed below.

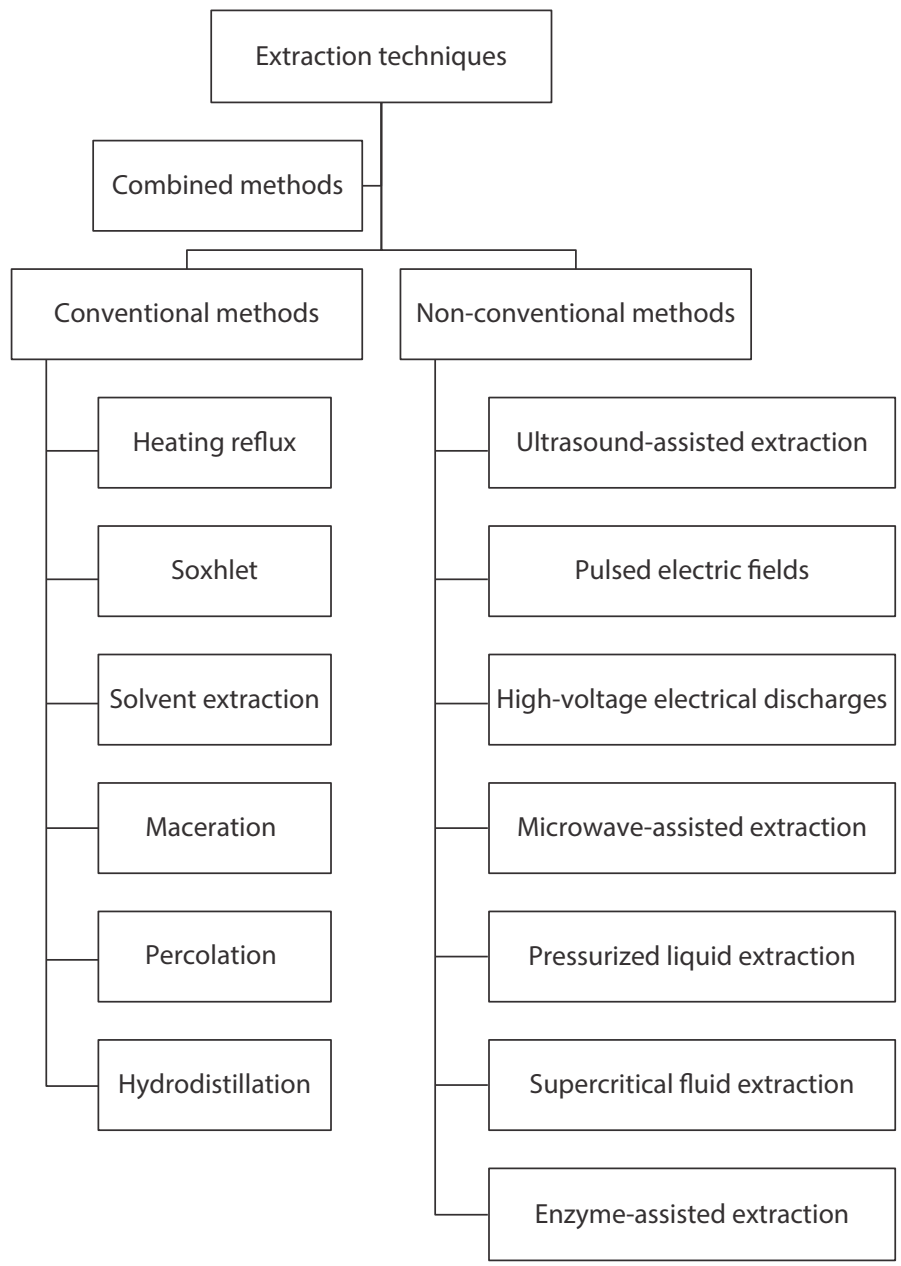

Figure 6.1 Conventional and nonconventional (innovative) methods used in the extraction of antioxidant compound from foodstuff. 


\subsubsection{Conventional Methods}

Conventional extraction of bioactive compounds from foodstuffs is time and solvent consuming, representing a serious energetic and environmental issue. Solid-liquid extraction can be defined as a mass transport phenomenon where compounds contained in foodstuff structure migrate into the solvent up to equilibrium. Examples include heating reflux, Soxhlet and solvent extraction, maceration, percolation, and hydrodistillation [135-139]. In plants, bioactive compounds exist enclosed in insoluble structures, such as cell vacuoles, which are not accessible to solvents. The use of heat to enhance mass transfer and reduce the extraction time can have deleterious effects, since high temperature can degrade thermolabile compounds $[140,141]$. Besides, the use of solvent mixtures containing acetone or methanol, pure or combined with water or an acid, is not in accordance with the green chemistry concept [142]. Because of this, alternative green solvents and novel extraction technologies based on physical mechanisms are being adopted.

\subsubsection{Nonconventional Methods}

The increasing need to extract bioactive molecules from natural sources has led to a deeper interest in new processes that can reduce the extraction time, processing temperature and solvent consumption, and contribute to higher extraction efficiency (i.e., yield and quality) and lower energy consumption as compared to conventional methods.

\subsection{Ultrasound-Assisted Extraction}

Ultrasound-assisted extraction (UAE) is one of the most used techniques in industry to enhance the mass transfer phenomena. The mass transfer rate is increased by cavitation forces; in this case the bubbles in the liquidsolid extraction can explosively collapse and generate localized hot spots (characterized by high temperature and pressure) causing plant tissue rupture and improving the release of intracellular substances into the solvent. UAE has been considered an economic method [143] and has already been applied to extract phenolics from spinach (Spinacea oleracea L.) [137], grape (Vitis vinifera L.) pomace [144], orange (Citrus sinensis L.) peels [145], sugar beet molasses [143] and phenolics and betacyanins from red pitaya (Hylocereus polyrhizus [Weber] Britton \& Rose) [140].

\subsection{Pulsed Electric Fields}

The pulsed electric fields (PEFs) treatment consists of the application of pulses of high voltage $(\mathrm{kV})$ and short duration $(\mu \mathrm{s}-\mathrm{ms})$ to a 
biological material placed between two electrodes. This voltage results in an electric field in which intensity depends on the voltage delivered and the gap between the electrodes. The originated phenomenon, called electroporation, consists of the increment of the cell membrane permeability to ions and macromolecules [146]. Therefore, PEF increases the extraction of high value-added compounds and can replace the enzymatic maceration of the process. PEFs have been applied to extract phenolics from papaya (Carica papaya L.) peels [136], polyphenols from grapes [147] and borage (Borago officinalis L.) leaves [146], phenolics and ascorbic acid from plum (Prunus domestica var. Casselman) and grape peels [148], as well as phenolics, vitamin C and carotenoids from stevia (Stevia rebaudiana Bertoni) leaves [149].

\subsection{High-Voltage Electrical Discharges}

High-voltage electrical discharges (HVEDs) have physical and mechanical effects on the product caused by shock waves. This technique introduces energy directly into an aqueous solution through a plasma channel formed by a high-voltage electrical discharge between two submerged electrodes [90]. The HVED mechanism is based on the electrical breakdown in water [150]. Air bubbles that are initially present in water or formed due to local heating are involved in this phenomenon and accelerate the process. If the electrical field is too intense, the avalanche of electrons becomes a starting point of streamer propagation from the high-voltage needle electrode to the grounded one. The electrical breakdown is accompanied by secondary phenomena (e.g., high-amplitude pressure shock waves, cavitation, and liquid turbulence) that cause particle fragmentation and cell structure damage, thus facilitating the release of intracellular compounds [142, 150]. When compared to other physical treatments, HVED results in a higher extraction rate than that obtained with PEF and ultrasounds. However, this process can originate very small particles that can lead to a more difficult solid-to-liquid separation step [150]. This technology have been used to extract phenolics from rapeseed (Brassica napus) [142] and papaya peels [136], anthocyanins from blackberries (Rubus fruticosus L.) [151], and phenolics, vitamin C and carotenoids from stevia [149].

\subsection{Microwave-Assisted Extraction}

Microwave-assisted extraction (MAE) has been rapidly developed as one of the hot-spot techniques for extracting high value-added compounds from different matrices. The extraction mechanism is based on the impact of microwaves on molecules by ionic conduction and dipole rotation inside target materials. The microwaves interact directly with the free 
water molecules present inside the materials, resulting in a rapid buildup of pressure within cells, and a pressure-driven enhanced mass transfer of target compounds out of the source material, which causes the rupture of the plant tissue and release of the active compounds into the extracting solvent $[133,152]$. During extraction, the solvent volume must be enough to ensure that the solid matrix is entirely immersed. The solvent choice is dictated by the solubility of the extracts of interest, by the interaction between solvent and plant matrix, and by the microwave absorbing properties of the solvent determined by its dielectric constant [153]. However, MAE can also be performed without the addition of any solvent $[90,154]$. Solvent-free microwave extraction (SFME) is based on a combination of microwave heating and dry distillation. The inherent benefits of SFME are reduction of pollution and handling costs resulting from the simplified manipulation procedure, easy clean-up and labor savings [154]. MAE has been applied to obtain phenolics from myrtle (Myrtus communis L.) leaves [153], horsetail (Equisetum arvense L.) [155], orange peels [145], false daisy (Eclipta prostrata Linn) [156], plum [152], tomatoes (Lycopersium esculentum L.) [157] and rice (Oryza sativa L.) grains [133], lycopene from tomato peels [101], and phenolics, vitamin C and carotenoids from stevia [149].

\subsection{Pressurized Liquid Extraction}

Pressurized liquid extraction (PLE), also known as accelerated or enhanced fluid extraction, or subcritical water extraction, is increasingly used in the extraction of antioxidants from different foodstuffs. This green technology involves the use of hot pressurized liquid solvents, including water or ethanol, below their critical point. The combination of high temperature and pressure enhances the extraction performance as compared with processes carried out at room temperature and atmospheric pressure. The temperature promotes higher analyte solubility by increasing both solubility and mass transfer rate and also decreases the viscosity and surface tension of solvents, thus improving extraction rate [158]. The setup of the technique also maintains samples in an $\mathrm{O}_{2}$ and light-free environment, which makes it preferable for use in the nutraceutical industry [159]. Furthermore, the addition of high concentrations of $\mathrm{CO}_{2}$ to pressurized liquid solvents enhances the kinetic desorption of analytes, inactivates unwanted enzymes that may destroy bioactive compounds, minimizes the use of liquid solvents, and reduces undesired concentration steps. Unlike MAE, PLE is not limited to solvents that can absorb microwaves [141]. Additionally, for extraction of polar compounds, PLE is considered as a potential alternative to supercritical fluid extraction (SFE). Recent studies have evaluated the suitability of this technology for the extraction of phenolics from 
mango (Mangifera indica L.) leaves [141] and roots of Scutellaria pinnatifida A. Hamilt. ssp. alpina (Bornm) Rech. f. [138], as well as carotenoids from kaki (Diospyros kaki L.), peach (Prunus persica L.), apricot (Prunus armeniaca L.) [160] and carrots (Daucus carota L.) [159].

\subsection{Supercritical Fluid Extraction}

Supercritical fluid extraction (SFE) has been used to extract target compounds from a variety of matrices at laboratory and commercial scale. Carbon dioxide is the main solvent used in this technique, especially when the target molecule is apolar. At supercritical conditions, above its critical temperature $\left(31.1^{\circ} \mathrm{C}\right)$ and pressure $(7.4 \mathrm{MPa}), \mathrm{CO}_{2}$ presents unique physicochemical properties because of its duality between liquid and pure gas [161]. Thus, it acquires very good mass-transfer properties because of its high, more gas-like diffusion coefficients and low viscosity values which provide effective penetration into solid matrices, and preserves the integrity and stability of more delicate compounds due to its relatively low surface tension $[162,163]$. In fact, this technique is adequate for thermolabile and oxidation-susceptible compounds [161]. Solvents other than $\mathrm{CO}_{2}$ are not necessarily required and the expense of removing organic solvents can be eliminated. Another advantage is its high selectivity and easy separation process from the extracted compounds without leaving toxic residues in extracts. Although high capital costs are associated with SFE, operating costs are relatively low and it is very simple to be scaled-up to industrial scale.

The SFE process has been used for the isolation of antioxidant compounds, including polyphenols [164], carotenoids, tocopherols and sitosterols [165]. Studies have demonstrated that SFE can be used to extract both hydrophilic and lipophilic compounds from plant matrices. However, compounds of appreciable polarity (e.g., phenols and flavonoids) are sparingly soluble in pure $\mathrm{CO}_{2}$; therefore, a polar modifier (co-solvent such as ethanol, methanol or water) must be added to obtain the necessary polarity to improve the extraction efficiency of polar compounds and to overcome interactions between the analyte and the matrix, facilitating the release of target compounds into the extraction medium. Accordingly, an efficient extraction of phenolics from Golden delicious apple peels and resveratrol from grape pomace using ethanol as co-solvent was achieved by Massias et al. [166] and Casas et al. [167], respectively. The extraction of protocatechuic acid from Scutellaria barbata D. Don [163] and phenolics from jatoba (Hymenaea courbaril L.) bark [168] was successfully achieved using water as co-solvent. Likewise, the extraction of proanthocyanidins from grape marc using $\mathrm{CO}_{2}$ as solvent and $10 \%$ ethanol-water mixture $(57 \%, \mathrm{v} / \mathrm{v})$ as 
co-solvent proved to be an efficient extraction method [169]. As an alternative to the addition of polar modifiers, it is possible to increase the pressure (and consequently the temperature) to decrease the interaction of polar compounds with the matrix and improve solubility [160].

\subsection{Enzyme-Assisted Extraction}

Enzyme-assisted extraction (EAE) is an eco-friendly method used to enhance the release and recovery of antioxidant compounds from plant matrices. Enzymes (either alone or in mixtures) can hydrolyze plant cell walls and eventually may enhance the recovery of both bound and free phenolics. The use of enzymes can increase the effect of solvent pretreatment, and either reduces the amount of solvent needed, or increases the yield of extractable compounds [90, 170]. EAE has been used successfully to increase the release of a variety of antioxidants, including phenolics from lemon balm (Melissa officinalis) [170] and bay (Laurus nobilis L.) leafs [171], polyphenols from ginger (Zingiber officinale Roscoe) [172], polysaccharides from Agaricus blazei Murrilli [173], and lycopene from tomato $[174,175]$. To improve the extractability of target compounds, the use of enzymes can be combined with other technologies [90]. However, the low range of temperatures and high cost is still a weak point of this technology.

\subsubsection{Extraction Solvents and Surfactants}

The preference of phenolic antioxidants for ethanol and methanol may be caused by their nonpolar part and the aliphatic fragment of alcohols. Bigger molecules prefer ethanol, as it can better "cover" the gaps between the hydrogen bonds [90]. Ethanol possesses GRAS (generally recognized as safe) status and the extracts can be used in the food industry. Aqueous ethanol offers many advantages as hydrophilic and lipophilic compounds are recovered together in different proportions and synergistic interactions occur inside the medium. Methanol is cheaper than ethanol but due to its toxicity it is not favored in the food industry [90]. On the other hand, carotenoids such as lycopene are more lipophilic and thereby polar aprotic (e.g., acetone) or nonpolar solvents (e.g., ethyl acetate) are preferred [176]. But, in this case, the solvent should be removed completely from the extract prior to its reutilization in food products. In fact, short-chain alcohols, especially ethanol and isopropanol, have been proposed as alternative extraction solvents for carotenoids and vitamin E [134].

The extraction and separation of phenolics may also be improved by using surfactants [177]. These surface active agents have both hydrophobic and hydrophilic components. When they are present at a concentration 
at or above their critical micellar concentration,it leads to the formation of multimodal compartments or micelles, which are capable of establishing interactions with either hydrophilic or lipophilic substances. These properties make surfactants useful in separation sciences and chromatographic application.

\subsubsection{Analytical Methodologies for Antioxidants}

Natural antioxidants have become a topic of great interest in the last decades. The chemical characteristics and also the bioactivities displayed by these molecules have a very important role in disease treatment and prevention. Thus, the full characterization of these compounds is mandatory for the understanding of their behavior and to establish a relationship between their chemical structure and the bioactivity displayed. Commonly used techniques for the detection, quantification and structure elucidation of antioxidant molecules in foodstuffs are schematized in Figure 6.2 and discussed below.

\subsubsection{Detection of Antioxidant Compounds}

After the optimization of the extraction conditions described in the previous sections, the extracts containing the target molecules are subjected to different processes to be isolated, identified and quantified. Those processes are adapted to the characteristics of each class of compounds. As stated before, there are different classes of antioxidants, namely phenolic compounds, vitamins and carotenoids, that are the major antioxidants found in natural matrices $[1,10]$.

In the last decades, several authors have developed different techniques to identify and determine the content of a specific molecule in different matrices after optimizing the most appropriate extraction technique, as described in the precious sections. From an initial approach, the authors usually perform colorimetric assays such as the Folin-Ciocalteu method that is used to determine "total phenolic compounds" present in a mixture since those are the major antioxidants found in natural matrices. This method is based on its ability to react with all the reducing species in the analyzed sample. This reagent is a mixture of tungsten and molybdenum that presents a yellow color, and under alkaline conditions it can react with the antioxidants, forming a complex that present a blue color and can be monitorized by a spectrophotometer. Due to its ability to react with all the reducing species suffering interferences, especially with reducing sugars and ascorbic acid, the Folin-Ciocalteu method is mostly used 


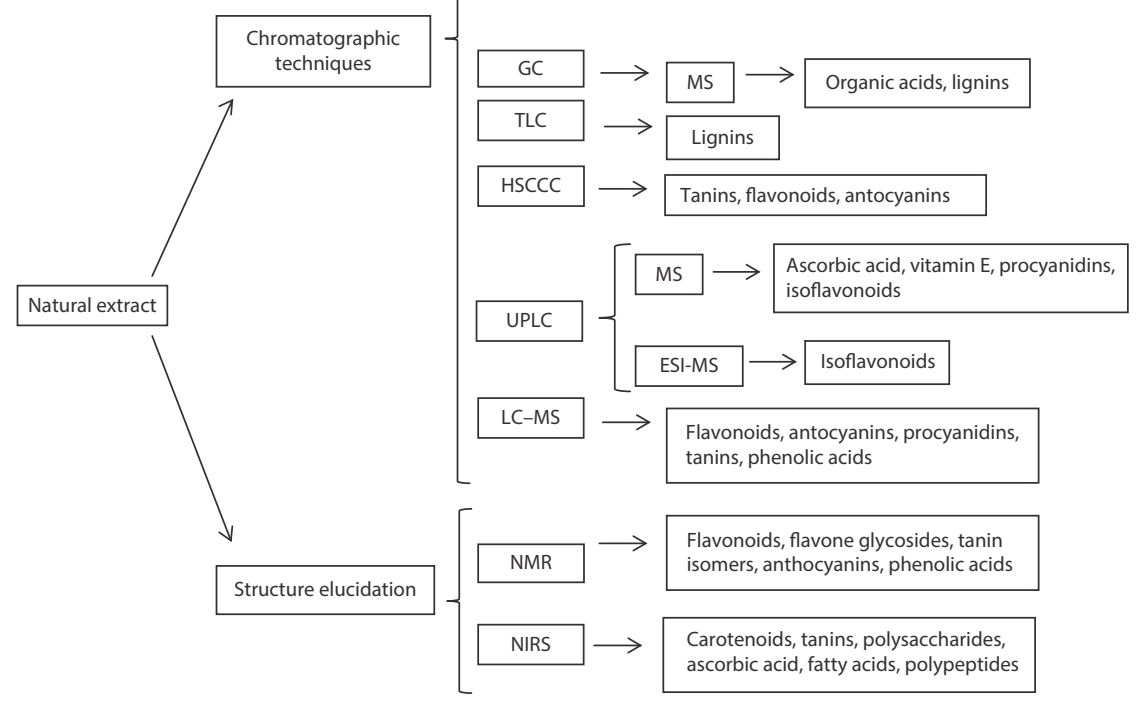

Figure 6.2 The most common techniques used for the detection, quantification and structure elucidation of antioxidants present in natural matrices. DAD (diode array detector); ESI-MS (electrospray ionization mass spectrometry); GC (gas chromatography); HPLC (high performance liquid chromatography); HSCCC (high speed contercurrent chromatography); LC-MS (liquid chromatography coupled to mass spectrometry); MS (mass spectrometry); NIRS (near infrared spectrometry); NMR (nuclear magnetic resonance); TLC (thin-layer chromatography); UPLC (ultra performance liquid chromatography); and UV-VIS (ultraviolet-visible).

to measure the reducing capacity rather than to determine the phenolic content $[10,178,179]$. Also, to determine ascorbic acid that is known for its reducing capacity, the method 2,6-dichlorophenol indophenol is used, taking advantage of this capacity displayed by ascorbic acid. It consists of a standardized solution of the oxidized dye that is titrated into a sample containing an unknown amount of ascorbic acid. Nevertheless, there is the possibility of error due to the slow reduction of the dye by other substances 
besides ascorbic acid and because of that this is not a specific method for the determination of this molecule [180]. Additionally, there are a large number of methods to evaluate the antioxidant activity of foodstuffs, e.g., in-vitro, in-vivo, electrochemical and chemiluminescent methods [90]. They allow measuring the total antioxidant activity conferred by the different compounds present in the foodstuff, but do not allow identifying the individual molecules responsible for such activity and the results vary depending on the mechanism of action of the selected assay [10]. These methods are usually performed as an initial screening, but are not precise and suffer the interference of other molecules present in the mixture, thus specific technologies for the determination of each molecule individually have been optimized.

\subsubsection{Determination of Individual Antioxidant Molecules}

\subsection{Chromatographic Techniques}

The most common techniques to determine individual molecules are high performance liquid chromatography (HPLC), gas chromatography (GC) and mass spectrometry (MS) (Figure 6.2) [10, 181, 182]. The most used technique is HPLC, offering precision and versatility. In most of the cases the studies are performed using a reversed-phase C18 column, being that the mobile phase usually is composed of two solvents containing methanol or acetonitrile as the polar organic solvents, and acidified water. HPLC can be coupled to different specific detectors; depending on the chemical features of the target molecules as for the determination of carotenoids and phenolic compounds, the HPLC is connected to UV-VIS and DAD (diode array), respectively [90, 181, 183].

This sophisticated technology is also used to determine vitamins, usually coupled to UV or DAD detectors [184]. With respect to tocopherols, Barros et al. [185] optimized the determination of these sensible molecules by HPLC coupled to a fluorescence detector, verifying that the fluorescence detector provided higher sensitivity than the UV detector, especially when the contents of the compounds to quantify are low, to achieve more satisfactory results.

Another chromatographic method is thin layer chromatography (TLC), known for its simplicity, low cost and ability to analyze a large number of samples with respect to the presence of antioxidants. This technique has been applied for the detection of lignins [90, 186, 187], and the fractions analyzed by TLC can be further identified by HPLC-MS or GC-MS $[90,188]$.

Another efficient technique in the determination of natural antioxidants such as organic acids is gas chromatography (GC), due to its excellent 
resolution. The disadvantage of this technique is the need of derivatization of the compounds that requires time, retarding the reproducibility of the analysis [189, 190]. Barros et al. [191] optimized the detection of organic acids using HPLC coupled to a diode array detector and verified that the method is reproducible and accurate and allowed compound separation in $8 \mathrm{~min}$.

High speed countercurrent chromatography (HSCCC) is one more detection technique that works without any solid stationary phase. This technology uses two immiscible liquid phases, one acts as the stationary phase and the other as the mobile phase, allowing soft separation conditions [192], which are very useful in the isolation of bioactive natural products [193], such as tannins [194], flavonoids [195] anthocyanins [196], allowing complete recovery and separation in large amounts.

In most of the cases, the HPLC is coupled to a specific detector, but also to mass spectrometry, allowing a separation of the molecules according to their differences in mass since the compounds present different fragmentation patterns that are useful in the identification of the present substances [197]. Several phenolic compounds have been identified in natural matrices with the help of mass spectrometry [90, 198, 199].

The use of liquid chromatography coupled to mass spectrometry (LC-MS) has been extensively used due to its high sensitivity in the detection and quantification of several antioxidant compounds in natural matrices such as flavonoids, anthocyanins, procyanidins, tannins [200] and phenolic acids [201]. On the other hand, HPLC-MS/MS is mostly used for the quantification of compounds that are present in very low amounts in the sample, such as vitamins A and E or $\beta$-carotene [90, 202]. Ultra performance liquid chromatography (UPLC) also exists, which presents higher sensitivity than HPLC; also, when coupled to ESI and/or MS it is described as being faster, consuming less amounts of eluent, presenting lower costs and taking less time for analysis. It is considered a very powerful technique for the rapid identification of secondary metabolites from natural antioxidants [90].

Several studies describe UPLC as being more sensitive than HPLC in the detection and quantification of antioxidant compounds from natural matrices such as ascorbic acid [203], vitamin E [204], procyanidins [205] and isoflavonoids [206].

High performance liquid chromatography-electrospray ionization mass spectrometry (HPLC/ESI-MS) is another chromatographic technique recently used for the detection and quantification of individual antioxidants [90]. This technique has been described as a very important tool capable of analyzing small and large molecules of different polarities in a 
complex sample. Taking advantage of the additional separation capabilities from mass spectrometry, the samples purification and the procedures for derivatization usually applied in GC-MS can be simplified [207].

Different authors have already used this technique in the identification and quantification of different compounds, such as tocols (tocopherols and tocotrienols), in different Triticum spp. [208]; flavonols from Hypericum perforatum [209]; and anthocyanins, flavan-3-ols, flavonols, hydroxycinnamic acids, hydroxybenzoic acids, and stilbenes in grape juice [210].

\subsection{Structure Elucidation of Individual Antioxidant Compounds} Since natural matrices are very complex, there are a lot of unknown compounds present in each plant, vegetable or other natural resources; thus, techniques are needed that can elucidate their chemical features (Figure 6.2) so their chemical structures can be designed and studied according to the chemical groups present in the compound [211,212]. For this purpose, nuclear magnetic resonance (NMR) is another important technique used for natural product structure analysis. 1H-NMR and 13C-NMR spectroscopy, respectively based on proton and carbon nuclear magnetic resonance, have been of extreme importance for the structure elucidation of natural compounds that allows a precise characterization of all the hydrogen and carbon bonds established between their self [211-213]. Furthermore, it is a rapid and nondestructive technique that can be performed without the use of an internal standard [90, 214]; quick sample preparation, short analysis time and total sample recovery are other important parameters to take advantage of NMR technology, which is why it has been described as a powerful tool for the identification of several compounds in the food matrix [211]. In the presence of a magnetic field, the NMR active nuclei (1H or 13C) absorb electromagnetic radiation at a frequency characteristic of the isotope. The resonant frequency, energy absorption, and the signal intensity are proportional to the magnetic field strength. The information obtained by the signals is related to the chemical and physical environments surrounding the spins, obtaining different information from each signal [215]. Another important advantage of this technology is that the signals obtained are proportional to the molar metabolite concentration, avoiding the need for calibration curves [90,216].

There are several reports which describe the combination of NMR with chromatographic techniques as a powerful tool for the structural elucidation of compounds [217, 218].

Several studies describe the use of NMR in the identification of different compounds present in natural matrices: epimeric forms of flavone glycosides [219]; tannin isomers [220]; anthocyanins [221]; rosmarinic acid [222]; 
para-hydroxy methyl benzoate glucoside, cycloeucalenol cis-ferulate, cycloeucalenol trans-ferulate, trans-ferulic acid, trans-ferulic acid methyl ester, cis-ferulic acid, cis-ferulic acid methyl ester, methyl caffeate, vanillic aldehyde and para-hydroxy benzaldehyde [223]; 9-O-(3-carboxymethyl4-(p-formylstyryl))hydroxybutanoic acid, 2-hydroxy-3-methoxycaffeic acid 5-O- $\beta$-D-glucopyranoside and $3^{\prime}$-O-methyl-4'-O-(4-O-galloyl- $\alpha$-Lrhamnopyranosyl) ellagic acid [224].

Near infrared spectrometry (NIRS) is another sensitive technology to help in the structural elucidation of antioxidants. This technique has been described as fast, noninvasive, low cost, non-polluting and nondestructive in the analysis of food matrices [90, 225]. It is a spectroscopic method that uses the near-infrared region of the electromagnetic spectrum within the wavelength range of about $700 \mathrm{~nm}$ to $2500 \mathrm{~nm}$. Near-infrared spectroscopy is a technique extensively used in agriculture for the determination of the quality of grain, fruits, vegetables, meat, among other agricultural products. Several studies are described in the literature reporting the use of NIRS for the determination of natural antioxidants: total carotenoids [226]; individual carotenoids such as lycopene and lutein [227, 228]; $\beta$-carotene [228]; malvidin-3-glucoside and tannins [229]; and polysaccharides [230]. In other studies, Pissard et al. [231] and Blanco-Díaz et al. [232] also determined ascorbic acid using NIRS. Polypeptides, fatty acids, esters and acids were also determined in cheese by this technology [233]; and fucoidan from Malaysian seaweeds [234].

\subsection{Conclusion}

Natural antioxidants are widely distributed in foodstuff, playing a very important role in helping the organism combat oxidative stress and related diseases. Moreover, these potent compounds have shown the ability to preserve several foods, increasing the products shelf life by decreasing oxidation phenomena. Due to the continuous interest in obtaining natural antioxidants, innovative and more sustainable technologies have been applied for the extraction of each class of these molecules according to particular chemical features. The development and the efficacy of these techniques have allowed the extraction of bioactives in high content, spending less in time, money and solvents, and preserving the bioactive features of these molecules. For analysis, there are a large number of specific technologies to determine total and individual antioxidants present in natural matrices. Taking advantage of the specific characteristics of the different available technologies, it is possible to determine and identify a large 
amount of individual antioxidants. Nevertheless, there is still the need of development more eco-friendly technologies and more specific tools to allow the identification of other molecules present in the natural matrices that are still unknown, since natural matrices are very complex and possess a large variety of different molecules.

\section{References}

1. Ferreira, I.C.F.R., Barros, L., and Abreu, R.M.V., Antioxidants in wild mushrooms. Curr. Med. Chem., 16, 1543-1560, 2009.

2. Halliwell, B., Free radicals and antioxidants-Quo vadis? Trends Pharmacol. Sci., 32(3), 125-130, 2011.

3. Duračková, Z., Some current insights into oxidative stress. Physiol. Res., 59, 459-469, 2010.

4. Ziech, D., Franco, R., Georgakilas, A.G., Georgakila, S., Malamou-Mitsi, V., Schoneveld, O., Pappa, A., and Panayiotidis, M.I., The role of reactive oxygen species and oxidative stress in environmental carcinogenesis and biomarker development. Chem. Biol. Interact., 188, 334-339, 2010.

5. Poljsak, B., Šuput, D., and Milisav, I., Achieving the balance between ROS and antioxidants: When to use the synthetic antioxidants. Oxid. Med. Cell. Longev., 2013, Article ID 956792, 2013. doi:10.1155/2013/956792.

6. Benzie, I.F.F., Evolution of dietary antioxidants. Comp. Biochem. Physiol. A, 136, 113-126, 2003.

7. Siegrist, M., Shi, J., Giusto, A., and Hartmann, C., Worlds apart: Consumer acceptance of functional foods and beverages in Germany and China. Appetite, 92, 87-93, 2015.

8. Wong, A.Y.T., Lai, J.M.C., and Chan, A.W.K., Regulations and protection for functional food products in the United States. J. Funct. Foods, 17, 540-551, 2015.

9. Embuscado, M.E., Spices and herbs: Natural sources of antioxidants-A mini review. J. Funct. Foods, doi: 10.1016/j.jff.2015.03.005, 2015.

10. Carocho, M., and Ferreira, I.C.F.R., A review on antioxidants, prooxidants and related controversy: Natural and synthetic compounds, screening and analysis methodologies and future perspectives. Food Chem. Toxicol., 51, 15-25, 2013.

11. Campbell, I. and Anaesthesia, Macronutrients, minerals, vitamins and energy. Intensive Care Med., 15, 344-349, 2014.

12. Nimalaratne, C., Sun, C., Wu, J., Curtis, J.M., and Schieber, A., Quantification of selected fat soluble vitamins and carotenoids in infant formula and dietary supplements using fast liquid chromatography coupled with tandem mass spectrometry. Food Res. Int., 66, 69-77, 2014.

13. Leboulanger, J., As Vitaminas: Bioquimica-Modo de Acção-Interesse Terapêutico, Lisboa: Roche, 1974. 
14. Jomova, K., and Valko, M., Health protective effects of carotenoids and their interactions with other biological antioxidants. Eur. J. Med. Chem., 70, 102-110, 2013.

15. Saini, R.K., Nile, S.H., and Park, S.W., Carotenoids from fruits and vegetables: Chemistry, analysis, occurrence, bioavailability and biological activities. Food Res. Int., 76, 735-750, 2015.

16. Kim, J.-Y. and Huber, K.C., Preparation and characterization of corn starch$\beta$-carotene composites. Carbohydr. Polym., 136, 394-401, 2016.

17. Ha, T.V.A., Kim, S., Choi, Y., Kwak, H.-S., Lee, S.J., Wenc, J., Oey, I., and Ko, S., Antioxidant activity and bioaccessibility of size-different nanoemulsions for lycopene-enriched tomato extract. Food Chem., 178, 115-121, 2015.

18. Breithaupt, D.E., Modern application of xanthophylls in animal feeding-A review. Trends Food Sci. Technol., 18, 501-506, 2007.

19. Lee, K.H., Pre- and co-treatment with xanthophyll enhances the anti-leukemic activity of adriamycin. J. Photochem. Photobiol. B, 92, 175-179, 2008.

20. Ruban, A.V. and Johnson, M.P., Xanthophylls as modulators of membrane protein function. Arch. Biochem. Biophys., 504, 78-85, 2010.

21. Kalantar-Zadeh, K., Leeb, G.H., and Block, G., Relationship between dietary antioxidants and childhood asthma: More epidemiological studies are needed. Med. Hypotheses, 62, 280-290, 2004.

22. Castel, V., Andrich, O., Netto, F.M., Santiago, L.G., and Carrara, C.R., Total phenolic content and antioxidant activity of different streams resulting from pilot-plant processes to obtain Amaranthus mantegazzianus protein concentrates. J. Food Eng., 122, 62-67, 2014.

23. Tapiero, H., Tew, K.D., Ba, N., and Mathé, G., Polyphenols: Do they play a role in prevention of human pathologies?. Biomed. Pharmacother., 56, 200-207, 2002.

24. Guan, Y., Chu, Q., Fu, L., Wu, T., and Ye, J., Determination of phenolic antioxidants by micellar electrokinetic capillary chromatography with electrochemical detection. Food Chem., 94, 157-162, 2006.

25. EFSA, Scientific opinion on the re-evaluation of butylated hydroxyanisole - BHA (E 320) as a food additive. EFSA J., 9(10), 2392, 2011. doi: 10.2903/j. efsa.2011.2392. Available at: http://www.efsa.europa.eu/en/efsajournal/ doc/2392.pdf.

26. EFSA, Scientific opinion on the re-evaluation of butylated hydroxytoluene BHT (E 321) as a food additive. EFSA J., 10(3), 2588, 2012. doi: 10.2903/j. efsa.2012.2588. Available at: http://www.efsa.europa.eu/en/efsajournal/ doc/2588.pdf.

27. Perrin, C. and Meyer, L., Quantification of synthetic phenolic antioxidants in dry foods by reversed-phase HPLC with photodiode array detection. Food Chem., 77, 93-100, 2002.

28. Mohamed, H.M.H., Mansour, H.A., Diaa, E.-D.M., and Farag, H., The use of natural herbal extracts for improving the lipid stability and sensory characteristics of irradiated ground beef. Meat Sci., 87, 33-39, 2011. 
29. Erkan, N., Ayranci, G., and Ayranci, E., Antioxidant activities of rosemary (Rosmarinus Officinalis L.) extract, blackseed (Nigella sativa L.) essential oil, carnosic acid, rosmarinic acid and sesamol. Food Chem., 110, 76-82, 2008.

30. Soyer, A., Ozalp, B., Dalmis, U., and Bilgin, V., Effects of freezing temperature and duration of frozen storage on lipid and protein oxidation in chicken meat. Food Chem., 120, 1025-1030, 2010.

31. Everse, J. and Hsia, N., The toxicities of native and modified hemoglobins. Free Radic. Biol. Med., 22, 1075-1099, 1997.

32. Alvarado, C.Z., Richards, M.P., O'Keefe, S.F., and Wang, H., The effect of blood removal on oxidation and shelf life of broiler breast meat. Poult. Sci., 86, 156-161, 2007.

33. Medina, I., Gallardo, J.M., and Aubourg, S.P., Quality preservation in chilled and frozen fish products by employment of slurry ice and natural antioxidants. Int. J. Food Sci. Tech., 44, 1467-1469, 2009.

34. Nissen, L.R., Byrne, D.V., Bertelsen, G., and Skibsted, L.H., The antioxidative activity of plant extracts in cooked pork patties as evaluated by descriptive sensory profiling and chemical analysis. Meat Sci., 68(3), 485-495, 2004.

35. Lara, M.S., Gutierrez, J.I., Timón, M., and Andrés, A.I., Evaluation of two natural extracts (Rosmarinus officinalis L. and Melissa officinalis L.) as antioxidants in cooked pork patties packed in MAP. Meat Sci., 88, 481-488, 2011.

36. Doolaege, E.H.A., Vossen, E., Raes, K., De Meulenaer, B., Verhé, R., Paelinck, H., and De Smet, S., Effect of rosemary extract dose on lipid oxidation, colour stability and antioxidant concentrations, in reduced nitrite liver pâtés. Meat Sci., 90, 925-931, 2012.

37. Georgantelis, D., Ambrosiadis, I., Katikou, P., Blekas, G., and Georgakis, S.A., Effect of rosemary extract, chitosan and a-tocopherol on microbiological parameters and lipid oxidation of fresh pork sausages stored at $4{ }^{\circ} \mathrm{C}$. Meat Sci., 76, 172-181, 2007.

38. Mohamed, H.M.H., Mansour, H.A., and Farag, M.D.E.H., The use of natural herbal extracts for improving the lipid stability and sensory characteristics of irradiated ground beef. Meat Sci., 87, 33-39, 2011.

39. Hygreeva, D., Pandey, M.C., and Radhakrishna, K., Potential applications of plant based derivatives as fat replacers, antioxidants and antimicrobials in fresh and processed meat products. Meat Sci., 98, 47-57, 2014.

40. Tironi, V.A., Tomás, M.C., and Añón, M.C., Quality loss during the frozen storage of sea salmon (Pseudopercis semifasciata). Effect of rosemary (Rosmarinus officinalis L.) extract. LWT-Food Sci. Technol., 43, 263-272, 2010.

41. Olmedo, R.H., Nepote, V., and Grosso, N.R., Preservation of sensory and chemical properties in flavoured cheese prepared with cream cheese base using oregano and rosemary essential oils. LWT-Food Sci. Technol., 53, 409-417, 2013.

42. Commission Directive 2010/67/EU. Official Journal of the European Union L, 277, 17-26 (21.10.2010), 2010. 
43. Commission Directive 2010/69/EU. Official Journal of the European Union L, 279, 22-31 (23.10.2010), 2010.

44. Shi, C., Cui, J., Yin, X., Luo, Y., and Zhou, Z., Grape seed and clove bud extracts as natural antioxidants in silver carp (Hypophthalmichthys molitrix) fillets during chilled storage: Effect on lipid and protein oxidation. Food Control, 40, 134-139, 2014.

45. Ahn, J.H., Grun, I.U., and Fernando, L.N., Antioxidant properties of natural plant extract containing polyphenolic compounds in cooked ground beef. J. Food Sci., 67, 1364-1369, 2002.

46. Özvural, E.B. and Vural, H., Grape seed flour is a viable ingredient to improve the nutritional profile and reduce lipid oxidation of frankfurters. Meat Sci., 88, 179-183, 2011.

47. Lau, D.W. and King, A.J., Pre- and post-mortem use of grape seed extract in dark poultry meat to inhibit development of thiobarbituric acid reactive substances. J. Agric. Food Chem., 51, 1602-1607, 2003.

48. Mielnik, M.B., Olsen, E., Vogt, G., Adeline, D., and Skrede, G., Grape seed extract as antioxidant in cooked, cold stored turkey meat. LWT-Food Sci. Technol., 39, 191-198, 2006.

49. Li, J., Hui, T., Wang, F., Li, S., Cui, B., Cui, Y., and Peng, Z., Chinese red pepper (Zanthoxylum bungeanum Maxim.) leaf extract as natural antioxidants in salted silver carp (Hypophthalmichthys molitrix) in dorsal and ventral muscles during processing. Food Control, 56, 9-17, 2015.

50. Qi, S., Huang, H., Huang, J., Wang, Q., and Wei, Q., Lychee (Litchi chinensis Sonn.) seed water extract as potential antioxidant and anti-obese natural additive in meat products. Food Control, 50, 195-201, 2015.

51. Ding, Y., Wang, S.-Y., Yang, D.-J., Chang, M.-H., and Chen, Y.-C., Alleviative effects of litchi (Litchi chinensis Sonn.) flower on lipid peroxidation and protein degradation in emulsified pork meatballs. J. Food Drug Anal., 23, 501-508, 2015.

52. Jongberg, S., Terkelsen, L.S., Miklos, R., and Lund, M.N., Green tea extract impairs meat emulsion properties by disturbing protein disulfide cross-linking. Meat Sci., 100, 2-9, 2015.

53. Bozkurt, H., Utilization of natural antioxidants: Green tea extract and Thymbra spicata oil in Turkish dry-fermented sausage. Meat Sci., 73, 442-450, 2006.

54. Martín-Diana, A.B., Rico, D., and Barry-Ryan, C., Green tea extract as a natural antioxidant to extend the shelf-life of fresh-cut lettuce. Innov. Food Sci. Emerg. Technol., 9, 593-603, 2008.

55. Mariutti, LR.B., Orlien, V., Bragagnolo, N., and Skibsted, L.H., Effect of sage and garlic on lipid oxidation in high-pressure processed chicken meat. Eur. Food Res. Technol., 227, 337-344, 2008.

56. Fasseas, M.K., Mountzouris, K.C., Tarantilis, P.A., Polissiou, M., and Zervas, G., Antioxidant activity in meat treated with oregano and sage essential oils. Food Chem., 106, 1188-1194, 2008. 
57. Carpenter, R., O'Grady, M.N., O'Callaghan, Y.C., O'Brien, N.M., and Kerry, J.P., Evaluation of the antioxidant potential of grape seed and bearberry extracts in raw and cooked pork. Meat Sci., 76, 604-610, 2007.

58. Lee, C.H., Reed, J.D., and Richards, M.P., Ability of various polyphenolic classes from cranberry to inhibit lipid oxidation in mechanically separated turkey and cooked ground pork. J. Muscle Foods, 17, 248-266, 2006.

59. Jayathilakan, K., Sharma, G.K., Radhakrishna, K., and Bawa, A.S., Antioxidant potential of synthetic and natural antioxidants and its effect on warmed-over-flavour in different species of meat. Food Chem., 105, 908-916, 2007.

60. Park, S.Y., Yoo, S.S., and Chin, K.B., Physicochemical properties, and antioxidant and antimicrobial effects of garlic and onion powder in fresh pork belly and loin during refrigerated storage. J. Food Sci., 73, C577-C584, 2008.

61. Naveena, B.M., Sen, A.R., Kingsly, R.P., Singh, D.B., and Kondaiah, N., Antioxidant activity of pomegranate rind powder extract in cooked chicken patties. Int. J. Food Sci. Technol., 43, 1807-1812, 2008.

62. Dias, M.I., Ferreira, I.C.F.R., and Barreiro, M.F., Microencapsulation of bioactives for food applications. Food Funct, 6, 1035-1052, 2015.

63. Gharsallaoui, A., Roudaut, G., Chambin, O., Voilley, A., and Saurel, R., Applications of spray-drying in microencapsulation of food ingredients: An overview. Food Res. Int., 40, 1107-1121, 2007.

64. Reineccius, G.A., in: Encapsulation and Controlled Release of Food Ingredients, S.J. Risch, G.A. Reineccius (Eds.), ACS Symposium Series, vol. 590, American Chemical Society, Washington, DC, 1993.

65. Shahidi, F., and Han, X.Q., Encapsulation of food ingredients. Crit. Rev. Food Sci. Nutr., 33, 501-547, 1993.

66. Seok, J.S., Kim, J.S., and Kwak, H.S., Microencapsulation of water-soluble isoflavone and physico-chemical property in milk. Arch. Pharm. Res., 26, 426-431, 2003.

67. Çam, M., İçyer, N.C., and Erdoğan, F., Pomegranate peel phenolics: Microencapsulation, storage stability and potential ingredient for functional food development. LWT-Food Sci. Technol., 55, 117-123, 2014.

68. Martins, A., Barros, L., Carvalho, A.M., Santos-Buelga, C., Fernandes, I.P., Barreiro, F., and Ferreira, I.C.F.R., Phenolic extracts of Rubus ulmifolius Schott flowers: Characterization, microencapsulation and incorporation into yogurts as nutraceutical sources. Food Funct., 5, 1091-1100, 2014.

69. Robert, P., García, P., Reyes, N., Chávez, J., and Santos, J., Acetylated starch and inulin as encapsulating agents of gallic acid and their release behaviour in a hydrophilic system. Food Chem., 134, 1-8, 2012.

70. Dias, M.I., Barros, L., Fernandes, I.P., Ruphuy, G., Oliveira, M.B.P.P., Santos-Buelga, C., Barreiro, M.F., and Ferreira, I.C.F.R., A bioactive formulation based on Fragaria vesca L. vegetative parts: Chemical characterization and application in k-carrageenan gelatin. J. Funct. Foods, 16, 243-255, 2015. 
71. Ribeiro, A., Ruphuy, G., Lopes, J.C., Dias, M.M., Barros, L., Barreiro, F., and Ferreira, I.C.F.R., Spray-drying microencapsulation of synergistic antioxidant mushroom extracts and their use as functional food ingredients. Food Chem., 188, 612-618, 2015.

72. Abbasi, S., Rahimi, S., and Azizi, M., Influence of microwave-microencapsulated citric acid on some sensory properties of chewing gum. J. Microencapsul., 26, 90-96, 2009.

73. Ezhilarasi, P.N., Indrani, D., Jena, B.S., and Anandharamakrishnana, C., Microencapsulation of Garcinia fruit extract by spray drying and its effect on bread quality. J. Sci. Food Agr., 94, 1116-1123, 2013.

74. Ezhilarasi, P.N., Indrani, D., Jena, B.S., and Anandharamakrishnan, C., Freeze drying technique for microencapsulation of Garcinia fruit extract and its effect on bread quality. J. Food Eng., 117, 513-520, 2013.

75. Pillai, D.S., Prabhasankar, B., Jena, B.S., and Anandharamakrishnan, C., Microencapsulation of Garcinia cowa fruit extract and effect of its use on pasta process and quality. Int. J. Food Prop., 15, 590-604, 2012.

76. Pasrija, D., Ezhilarasi, P.N., Indrani, D., and Anandharamakrishnan, C., Microencapsulation of green tea polyphenols and its effect on incorporated bread quality. LWT-Food Sci. Technol., 64, 289-296, 2015.

77. Rubilar, M., Morales, E., Contreras, K., Ceballos, C., Acevedo, F., Villarroel, M., and Shene, C., Development of a soup powder enriched with microencapsulated linseed oil as a source of omega-3 fatty acids. Eur. J. Lipid Sci. Technol., 114, 423-433, 2012.

78. Stratulat, I., Britten, M., Salmieri, S., Fustier, P., St-Gelais, D., Champagne, C.P., Lacroix, M., Enrichment of cheese with bioactive lipophilic compounds. J. Funct. Foods, 6, 48-59, 2014.

79. Moore, M.E., Han, I.Y., Acton, J.C., Ogale, A.A., Barmore, C.R., and Dawson, P.L., Effects of antioxidants in polyethylene film on fresh beef color. J. Food Sci., 68, 99-104, 2000.

80. Nerín, C., Tovar, L., Djenane, D., Camo, J., Salafranca, J., Beltrán, J.A., and Roncalés, P., Stabilization of beef meat by new active packaging containing natural antioxidants. J. Agric. Food Chem., 54, 7840-7846, 2006.

81. Camo, J., Lorés, A., Djenane, D., Beltrán, J.A., and Roncalés, P., Display life of beef packaged with an antioxidant active film as a function of the concentration of oregano extract. Meat Sci., 88, 174-178, 2011.

82. Calatayud, M., López-de-Dicastillo, C., López-Carballo, G., Vélez, D., Muñoz, P.H., and Gavara, R., Active films based on cocoa extract with antioxidant, antimicrobial and biological applications. Food Chem., 139, 51-58, 2013.

83. Yang, H.-J., Lee, J.-H., Wonb, M., and Song, K.B., Antioxidant activities of distiller dried grains with solubles as protein films containing tea extracts and their application in the packaging of pork meat. Food Chem., 196, 174-179, 2016.

84. Jalilzadeh, A., Tunçtürk, Y., and Hesari, J., Extension shelf life of cheese: A review. Int. J. Dairy Sci., 10(2), 44-60, 2015. 
85. Barbosa-Pereira, L., Cruz, J.M., Sendón, R., de Quirós, A.R.B., Ares, A., Castro-López, M., Abad, M.J., Maroto, J., and Paseiro-Losada, P., Development of antioxidant active films containing tocopherols to extend the shelf life of fish. Food Control, 31, 236-243, 2013.

86. Siró, I., Kápolna, E., Kápolna, B., and Lugasi, A., Functional food. Product development, marketing and consumer acceptance-A review. Appetite, 51, 456-467, 2008.

87. Xu, J., Su, X., Lim, S., Griffin, J., Carey, E., Katz, B., Tomich, J., Smith, J.S., and Wang, W., Characterisation and stability of anthocyanins in purple-fleshed sweet potato P40. Food Chem., 186, 90-96, 2015.

88. Isabelle, M., Lee, B.L., Lim, M.T., Koh, W.-P., Huang, D., and Ong, C.N., Antioxidant activity and profiles of common vegetables in Singapore. Food Chem., 120, 993-1003, 2010.

89. Liu, F., Wang, L., Gu, L., Zhao, W., Su, H., and Cheng, X., Higher transcription levels in ascorbic acid biosynthetic and recycling genes were associated with higher ascorbic acid accumulation in blueberry. Food Chem., 188, 399-405, 2015.

90. Oroian, M. and Escriche, I., Antioxidants: Characterization, natural sources, extraction and analysis. Food Res. Int., 74, 10-36, 2015.

91. Tamasi, G., Cambi, M., Gaggelli, N., Autino, A., Cresti, M., and Cini, R., The content of selected minerals and vitamin $\mathrm{C}$ for potatoes (Solanum tuberosum L.) from the high Tiber Valley area, southeast Tuscany. J. Food Comp. Anal., 41, 157-164, 2015.

92. Sen, C.K., Khanna, S., and Roy, S., Tocotrienols: Vitamin E beyond tocopherols. Life Sci., 78, 2088-2098, 2006.

93. Do, T.D.T., Cozzolino, D., Muhlhausler, B., Box, A., and Able, A.J., Antioxidant capacity and vitamin E in barley: Effect of genotype and storage Food Chem., 187, 65-74, 2015.

94. Taş, N.G. and Gökmen, V., Profiling triacylglycerols, fatty acids and tocopherols in hazelnut varieties grown in Turkey. J. Food Comp. Anal., 44, 115-121, 2015.

95. Vrolijk, M.F., Opperhuizen, A., Jansen, E.H.J.M., Godschalk, R.W., VanSchooten, F.J., Bast, A., and Haenen, G.R.M.M., The shifting perception on antioxidants: the case of vitamin $\mathrm{E}$ and $\beta$-carotene. Redox Biol., 4, 272-278, 2015.

96. Damon, M., Zhang, N.Z., Haytowitz, D.B., and Booth, S.L., Phylloquinone (vitamin $\mathrm{K}_{1}$ ) content of vegetables. J. Food Comp. Anal., 18, 751-758, 2005.

97. Suttie, J.W. and Booth, S.L., Vitamin K1. Adv. Nutr., 2, 440-441, 2011.

98. Presse, N., Potvin, S., Bertrand, B., Calvo, M.S., and Ferland, G., Phylloquinone content of herbs, spices and seasonings. J. Food Comp. Anal., 41, 15-20, 2015.

99. Wu, X., Sun, C., Yang, L., Zeng, G., Liu, Z., and Li, Y., $\beta$-carotene content in sweet potato varieties from China and the effect of preparation on $\beta$-carotene retention in the Yanshu No. 5. Innov. Food Sci. Emerg. Technol., 9, 581-586, 2008 . 
100. Krinsky, N.I. and Johnson, E.J., Carotenoid actions and their relation to health and disease. Mol. Aspects Med., 26, 459-516, 2005.

101. Ho, K.K.H.Y., Ferruzzi, M.G., Liceaga, A.M., and San Martín-González, M.F., Microwave-assisted extraction of lycopene in tomato peels: Effect of extraction conditions on all-trans and cis-isomer yields. LWT-Food Sci. Technol., 62, 160-168, 2015.

102. Poojary, M.M. and Passamonti, P., Extraction of lycopene from tomato processing waste: Kinetics and modelling. Food Chem., 173, 943-950, 2015.

103. Tsui, E.M. and Cheryan, M., Membrane processing of xanthophylls in ethanol extracts of corn. J. Food Eng., 83, 590-595, 2007.

104. Brulc, L., Simonovska, B., Vovk, I., and Glavnik, V., Determination of egg yolk xanthophylls by isocratic high-performance liquid chromatography. J. Chromatogr. A, 1318, 134-141, 2013.

105. Hu, B., Roy, L.A., and Davis, D.A., Correlations of xanthophylls in catfish fillets, plankton, shad and snails in catfish production ponds in west Alabama. Aquaculture, 402-403, 46-49, 2013.

106. Scalbert, A., Manach, C., Morand, C., Rémésy, C., and Jiménez, L., Dietary polyphenols and the prevention of diseases. Crit. Rev. Food Sci. Nutr., 45, 287-306, 2005.

107. Huber, L.S., Hoffmann-Ribani, R., and Rodriguez-Amaya, D.B., Quantitative variation in Brazilian vegetable sources of flavonols and flavones. Food Chem., 113, 1278-1282, 2009.

108. Hostetler, G.L., Riedl, K.M., and Schwartz, S.J., Effects of food formulation and thermal processing on flavones in celery and chamomile. Food Chem., 141, 1406-1411, 2013.

109. Ivanovic, J., Tadic, V., Dimitrijevic, S., Stamenic, M., Petrovic, S., and Zizovic, I., Antioxidant properties of the anthocyanin-containing ultrasonic extract from blackberry cultivar "Čačanska Bestrna”. Ind. Crop. Prod., 53, 274-281, 2014.

110. Li, S., Chen, G., Zhang, C., Wu, M., Wu, S., and Liu, Q., Research progress of natural antioxidants in foods for the treatment of diseases. Food Sci. Human Wellness, 3, 110-116, 2014.

111. Ganzera, M., Supercritical fluid chromatography for the separation of isoflavones. J. Pharm. Biomed. Anal., 107, 364-369, 2015.

112. Gras, C.C., Carle, R., and Schweiggert, R.M., Determination of anthocyanins from black carrots by UHPLC-PDA after ultrasound-assisted extraction. J. Food Comp. Anal., 44, 170-177, 2015.

113. Harb, J., Alseekh, S., Tohge, T., and Fernie, A.R., Profiling of primary metabolites and flavonols in leaves of two table grape varieties collected from semiarid and temperate regions. Phytochemistry, 117, 444-455, 2015.

114. Lee, M.J., Chung, I.-M., Kim, H., and Jung, M.Y., High resolution LC-ESITOF-mass spectrometry method for fast separation, identification, and quantification of 12 isoflavones in soybeans and soybean products. Food Chem., 176, 254-262, 2015. 
115. Mølmann, J.A.B., Steindal, A.L.H., Bengtsson, G.B., Seljåsen, R., Lea, P., Skaret, J., and Johansen, T.J., Effects of temperature and photoperiod on sensory quality and contents of glucosinolates, flavonols and vitamin $\mathrm{C}$ in broccoli florets. Food Chem., 172, 47-55, 2015.

116. Qin, Y., Liang, Y., Ren, D., Qiu, X., and Li, X., Separation of phenolic acids and flavonoids from Trollius chinensis Bunge by high speed counter-current chromatography. J. Chromatogr. B, 1001, 82-89, 2015.

117. Ruiz, A., Bustamante, L., Vergara, C., von Baer, D., Hermosín-Gutiérrez, I., Obando, L., and Mardones, C., Hydroxycinnamic acids and flavonols in native edible berries of South Patagonia. Food Chem., 167, 84-90, 2015.

118. Ramirez, J.E., Zambrano, R., Sepúlveda, B., Kennelly, E.J., and Simirgiotis, M.J., Anthocyanins and antioxidant capacities of six Chilean berries by HPLC-HR-ESI-ToF-MS. Food Chem., 176, 106-114, 2015.

119. Pedro, A.C., Granato, D., and Rosso, N.D., Extraction of anthocyanins and polyphenols from black rice (Oryza sativa L.) by modeling and assessing their reversibility and stability. Food Chem., 191, 12-20, 2016.

120. Jeszka-Skowron, M., Krawczyk, M., and Zgoła-Grześkowiak, A., Determination of antioxidant activity, rutin, quercetin, phenolic acids and trace elements in tea infusions. Influence of citric acid addition on extraction of metals. J. Food Comp. Anal., 40, 70-77, 2015.

121. Martini, D., D’Egidio, M.G., Nicoletti, I., Corradini, D., and Taddei, F., Effects of durum wheat debranning on total antioxidant capacity and on content and profile of phenolic acids. J. Funct. Foods, 17, 83-92, 2015.

122. Taofiq, O., Calhelha, R.C., Heleno, S., Barros, L., Martins, A., SantosBuelga, C., Queiroz, M.J.R.P., and Ferreira, I.C.F.R., The contribution of phenolic acids to the anti-inflammatory activity of mushrooms: Screening in phenolic extracts, individual parent molecules and synthesized glucuronated and methylated derivatives. Food Res. Int., 76, 821-827, 2015.

123. Hosu, A., Cristea, V.-M., and Cimpoiu, C., Analysis of total phenolic, flavonoids, anthocyanins and tannins content in Romanian red wines: Prediction of antioxidant activities and classification of wines using artificial neural networks. Food Chem., 150, 113-118, 2014

124. Muhacir-Güzel, N., Türkyılmaz, M., Yemiş, O., Taği, S., and Özkan, M., Changes in hydrolysable and condensed tannins of pomegranate (Punica granatum L., $c v$. Hicaznar) juices from sacs and whole fruits during production and their relation with antioxidant activity. LWT-Food Sci. Technol., 59, 933-940, 2014.

125. Figueroa-Espinoza, M.C., Zafimahova, A., Alvarado, P.G.M., Dubreucq, E., and Poncet-Legrand, C., Grape seed and apple tannins: Emulsifying and antioxidant properties. Food Chem., 178, 38-44, 2015.

126. Grippi, F., Crosta, L., Aiello, G., Tolomeo, M., Oliveri, F., Gebbia, N., and Curione, A., Determination of stilbenes in Sicilian pistachio by high-performance liquid chromatographic diode array (HPLC-DAD/FLD) and evaluation of eventually mycotoxin contamination. Food Chem., 107, 483-488, 2008. 
127. Kasiotis, K.M., Pratsinis, H., Kletsas, D., and Haroutounian, S.A., Resveratrol and related stilbenes: Their anti-aging and anti-angiogenic properties. Food Chem. Toxicol., 61, 112-120, 2013.

128. Silva, F., Figueiras, A., Gallardo, E., Nerín, C., and Domingues, F.C., Strategies to improve the solubility and stability of stilbene antioxidants: A comparative study between cyclodextrins and bile acids. Food Chem., 145, 115-125, 2014.

129. Xie, L. and Bolling, B.W., Characterisation of stilbenes in California almonds (Prunus dulcis) by UHPLC-MS. Food Chem., 148, 300-306, 2014.

130. Thompson, L.U., Boucher, B.A., Liu, Z., Cotterchio, M., and Kreiger, N., Phytoestrogen content of foods consumed in Canada, including isoflavones, lignans, and coumestan. Nutr. Cancer, 54, 184-201, 2006.

131. Durazzo, A., Turfani, V., Azzini, E., Maiani, G., and Carcea, M., Phenols, lignans and antioxidant properties of legume and sweet chestnut flours. Food Chem., 140, 666-671, 2013.

132. Edel, A.L., Pierce, G.N., and Aliani, M., Age-dependency in the metabolism of flaxseed lignans by healthy adults. J. Funct. Foods, 17, 948-957, 2015.

133. Setyaningsih, W., Saputro, I.E., Palma, M., and Barroso, C.G., Optimisation and validation of the microwave-assisted extraction of phenolic compounds from rice grains. Food Chem., 169, 141-149, 2015.

134. Baiano, A. and Del Nobile, M.A., Antioxidant compounds from vegetable matrices: Biosynthesis, occurrence, and extraction systems. Crit. Rev. Food Sci. Nutr., 2015. DOI: 10.1080/10408398.2013.812059.

135. Pinela, J., Barros, L., Carvalho, A.M., and Ferreira, I.C.F.R., Nutritional composition and antioxidant activity of four tomato (Lycopersicon esculentum L.) farmer' varieties in Northeastern Portugal homegardens. Food Chem. Toxicol., 50, 829-834, 2012.

136. Parniakov, O., Barba, F.J., Grimi, N., Lebovka, N., and Vorobiev, E., Impact of pulsed electric fields and high voltage electrical discharges on extraction of high-added value compounds from papaya peels. Food Res. Int., 65, 337-343, 2014.

137. Altemimi, A., Choudhary, R., Watson, D.G., and Lightfoot, D.A., Effects of ultrasonic treatments on the polyphenol and antioxidant content of spinach extracts. Ultrason. Sonochem., 24, 247-255, 2015.

138. Golmakani, E., Mohammadi, A., Ahmadzadeh Sani, T., and Kamali, H., Phenolic and flavonoid content and antioxidants capacity of pressurized liquid extraction and perculation method from roots of Scutellaria pinnatifida A. Hamilt. subsp alpina (Bornm) Rech. f. J. Supercrit. Fluids, 95, 318-324, 2014.

139. Uribe, E., Delgadillo, A., Giovagnoli-Vicuña, C., Quispe-fuentes, I., and Zura-bravo, L., Extraction techniques for bioactive compounds and antioxidant capacity determination of Chilean papaya (Vasconcellea pubescens) fruit. J. Chem., 2015, Article ID 347532, 2015.

140. Ramli, N.S., Ismail, P., and Rahmat, A., Influence of conventional and ultrasonic-assisted extraction on phenolic contents, betacyanin contents, and antioxidant capacity of red dragon fruit (Hylocereus polyrhizus). Sci. World J., 2014, Article ID 964731, 2014. 
141. Fernández-Ponce, M.T., Casas, L., Mantell, C., Martínez, E., and Ossa, D., Use of high pressure techniques to produce Mangifera indica L. leaf extracts enriched in potent antioxidant phenolic compounds. Innov. Food Sci. Emerg. Technol., 29, 94-106, 2015.

142. Barba Orellana, F.J., Boussetta, N., and Vorobiev, E., Emerging technologies for the recovery of isothiocyanates, protein and phenolic compounds from rapeseed and rapeseed press-cake: Effect of high voltage electrical discharges. Innov. Food Sci. Emerg. Technol., 2015. DOI: 10.1016/j.ifset.2015.06.008.

143. Chen, M., Zhao, Y., and Yu, S., Optimisation of ultrasonic-assisted extraction of phenolic compounds, antioxidants, and anthocyanins from sugar beet molasses. Food Chem., 172, 543-550, 2015.

144. González-Centeno, M.R., Comas-Serra, F., Femenia, A., Rosselló, C., and Simal, S., Effect of power ultrasound application on aqueous extraction of phenolic compounds and antioxidant capacity from grape pomace (Vitis vinifera L.): Experimental kinetics and modeling. Ultrason. Sonochem., 22, 506-514, 2015.

145. Nayak, B., Dahmoune, F., Moussi, K., Remini, H., Dairi, S., Aoun, O., and Khodir, M., Comparison of microwave, ultrasound and accelerated-assisted solvent extraction for recovery of polyphenols from Citrus sinensis peels. Food Chem., 187, 507-516, 2015.

146. Segovia, F.J., Luengo, E., Corral-Pérez, J.J., Raso, J., and Almajano, M.P., Improvements in the aqueous extraction of polyphenols from borage (Borago officinalis L.) leaves by pulsed electric fields: Pulsed electric fields (PEF) applications. Ind. Crop. Prod., 65, 390-396, 2015.

147. Delsart, C., Cholet, C., Ghidossi, R., Grimi, N., Gontier, E., Gény, L., Vorobiev, E., and Mietton-Peuchot, M., Effects of pulsed electric fields on Cabernet Sauvignon grape berries and on the characteristics of wines, food and bioprocess technology. Food Bioprocess Tech., 7, 424-436, 2014.

148. Medina-Meza, I.G. and Barbosa-Cánovas, G.V., Assisted extraction of bioactive compounds from plum and grape peels by ultrasonics and pulsed electric fields. J. Food Eng., 166, 268-275, 2015.

149. Barba, F.., Grimi, N., and Vorobiev, E., Evaluating the potential of cell disruption technologies for green selective extraction of antioxidant compounds from Stevia rebaudiana Bertoni leaves. J. Food Eng., 149, 222-228, 2015.

150. Boussetta, N. and Vorobiev, E., Extraction of valuable biocompounds assisted by high voltage electrical discharge: A review. C.R. Chim., 17, 197-203, 2014.

151. Barba, F.J., Galanakis, C.M., Esteve, M.J., Frigola, A., and Vorobiev, E., Potential use of pulsed electric technologies and ultrasounds to improve the recovery of high-added value compounds from blackberries. J. Food Eng., 167A, 38-44, 2015.

152. Haddadi-Guemghar, H., Janel, N., Dairou, J., Remini, H., and Madani, K., Optimisation of microwave-assisted extraction of prune (Prunus domestica) antioxidants by response surface methodology. Int. J. Food Sci. Technol., 49, 2158-2166, 2014. 
153. Dahmoune, F., Nayak, B., Moussi, K., Remini, H., and Madani, K., Optimization of microwave-assisted extraction of polyphenols from Myrtus communis L. leaves. Food Chem., 166, 585-595, 2015.

154. Li, Y., Fabiano-Tixier, A.S., Vian, M.A., and Chemat, G., Solvent-free microwave extraction of bioactive compounds provides a tool for green analytical chemistry. TrAC-Trend. Anal. Chem., 47, 1-11, 2013.

155. Milutinović, M., Radovanović, N., Rajilić-Stojanović, M., Šiler-Marinković, S., Dimitrijević, S., and Dimitrijević-Branković, S., Microwave-assisted extraction for the recovery of antioxidants from waste Equisetum arvense. Ind. Crop. Prod., 61, 388-397, 2014.

156. Fang, X., Wang, J., Hao, J., Li, X., and Guo, N., Simultaneous extraction, identification and quantification of phenolic compounds in Eclipta prostrata using microwave-assisted extraction combined with HPLC-DAD-ESI-MS/ MS. Food Chem., 188, 527-536, 2015.

157. Li, H., Deng, Z., Wu, T., Liu, R., Loewen, S., and Tsao, R., Microwave-assisted extraction of phenolics with maximal antioxidant activities in tomatoes. Food Chem., 130, 928-936, 2012.

158. Azmir, J., Zaidul, I.S.M., Rahman, M.M., Sharif, K.M., Mohamed, A., Sahena F., Jahurul, M.H.A., Ghafoor, K., Norulaini, N.A.N., and Omar, A.K.M., Techniques for extraction of bioactive compounds from plant materials: A review. J. Food Eng., 117, 426-436, 2013.

159. Saha, S., Walia, S., Kundu, A., Sharma, K., and Paul, R.K., Optimal extraction and fingerprinting of carotenoids by accelerated solvent extraction and liquid chromatography with tandem mass spectrometry. Food Chem., 177, 369-375, 2015.

160. Zaghdoudi, K., Pontvianne, S., Framboisier, X., Achard, M., Kudaibergenova, R., Ayadi-Trabelsi, M., Kalthoum-cherif, J., Vanderesse, R., Frochot, C., and Guiavarc'h, Y., Accelerated solvent extraction of carotenoids from: Tunisian Kaki (Diospyros kaki L.), peach (Prunus persica L.) and apricot (Prunus armeniaca L.). Food Chem., 184, 131-139, 2015.

161. Cardenas-Toro, F.P., Forster-Carneiro, T., Rostagno, M.A., Petenate, A.J., Maugeri Filho, F., and Meireles, M.A.A., Integrated supercritical fluid extraction and subcritical water hydrolysis for the recovery of bioactive compounds from pressed palm fiber. J. Supercrit. Fluids, 93, 42-48, 2014.

162. Rawson, A., Tiwari, B.K., Brunton, N., Brennan, C., Cullen, P.J., and O'Donnell, C.P., Application of supercritical carbon dioxide to fruit and vegetables: Extraction, processing, and preservation. Food Rev. Int., 28, 253-276, 2012.

163. Yang, Y.C., Wei, M.C., Huang, T.C., and Lee, S.Z., Extraction of protocatechuic acid from Scutellaria barbata D. Don using supercritical carbon dioxide. J. Supercrit. Fluids, 81, 55-66, 2013.

164. Sanjaya, R.E., Tedjo, Y.Y., Kurniawan, A., Ju, Y.H., Ayucitra, A., and Ismadji, S., Investigation on supercritical $\mathrm{CO} 2$ extraction of phenolic-phytochemicals 
from an epiphytic plant tuber (Myrmecodia pendans). J. CO2 Util., 6, 26-33, 2014.

165. Vági, E., Simándi, B., Vásárhelyiné, K.P., Daood, H., Kéry, Á., Doleschall, F., and Nagy, B., Supercritical carbon dioxide extraction of carotenoids, tocopherols and sitosterols from industrial tomato by-products. J. Supercrit. Fluids, 40, 218-226, 2007.

166. Massias, A., Boisard, S., Baccaunaud, M., Leal Calderon, F., and SubraPaternault, P., Recovery of phenolics from apple peels using $\mathrm{CO}_{2+}$ ethanol extraction: Kinetics and antioxidant activity of extracts. J. Supercrit. Fluids, 98, 172-182, 2015.

167. Casas, L., Mantell, C., Rodríguez, M., La Ossa, E.J.M.D., Roldán, A., De Ory, I., Caro, I., and Blandino, A., Extraction of resveratrol from the pomace of Palomino fino grapes by supercritical carbon dioxide. J. Food Eng., 96, 304-308, 2010.

168. Veggi, P.C., Prado, J.M., Bataglion, G.A., Eberlin, M.N., and Meireles, M.A.A., Obtaining phenolic compounds from jatoba (Hymenaea courbaril L.) bark by supercritical fluid extraction. J. Supercrit. Fluids, 89, 68-77, 2014.

169. Da Porto, C., Natolino, A., and Decorti, D., Extraction of proanthocyanidins from grape marc by supercritical fluid extraction using $\mathrm{CO}_{2}$ as solvent and ethanol-water mixture as co-solvent. J. Supercrit. Fluids, 87, 59-64, 2014.

170. Miron, T.L., Herrero, M., and Ibáñez, E., Enrichment of antioxidant compounds from lemon balm (Melissa officinalis) by pressurized liquid extraction and enzyme-assisted extraction. J. Chromatogr. A, 1288, 1-9, 2013.

171. Boulila, A., Hassen, I., Haouari, L., Mejri, F., Ben Amor, I., Casabianca, H., and Hosni, K., Enzyme-assisted extraction of bioactive compounds from bay leaves (Laurus nobilis L.). Ind. Crop. Prod., 74, 485-493, 2015.

172. Nagendra Chari, K.L., Manasa, D., Srinivas, P., and Sowbhagya, H.B., Enzyme-assisted extraction of bioactive compounds from ginger (Zingiber officinale Roscoe). Food Chem., 139, 509-514, 2013.

173. Jia, S., Li, F., Liu, Y., Ren, H., Gong, G., Wang, Y., and Wu, S., Effects of extraction methods on the antioxidant activities of polysaccharides from Agaricus blazei Murrill. Int. J. Biol. Macromolec., 62, 66-69, 2013.

174. Ranveer, R.C., Patil, S.N., and Sahoo, A.K., Effect of different parameters on enzyme-assisted extraction of lycopene from tomato processing waste. Food Bioprod. Process., 91, 370-375, 2013.

175. Zuorro, A., Fidaleo, M., and Lavecchia, R., Enzyme-assisted extraction of lycopene from tomato processing waste. Enzyme Microb. Technol., 49, 567-573, 2011.

176. Strati, I.F. and Oreopoulou, V., Effect of extraction parameters on the carotenoid recovery from tomato waste. Int. J. Food Sci. Tech., 46, 23-29, 2011.

177. Sharma, S., Kori, S., and Parmar, A., Surfactant mediated extraction of total phenolic contents (TPC) and antioxidants from fruits juices. Food Chem., 185, 284-288, 2015. 
178. Huang, D., Ou, B., and Prior, R.L., The chemistry behind antioxidant capacity assays. J. Agric. Food Chem., 53, 1841-1856, 2005.

179. García-Guzmán, J.J., Hernández-Artiga, M.P., León, L.P.P., and BellidoMilla, D., Selective methods for polyphenols and sulphur dioxide determination in wines. Food Chem., 182, 47-54, 2015.

180. Highet, D.M. and West, E.S., A procedure for the determination of ascorbic acid based upon the use of a standardized solution of 2,6-dichlorophenol indophenol in xylene. J. Biol. Chem., 146, 655-662, 1942.

181. Barros, L., Dueñas, M., Ferreira, I.C.F.R., Baptista, P., and Santos-Buelga, C., Phenolic acids determination by HPLC-DAD-ESI/MS in sixteen different Portuguese wild mushrooms species. Food Chem. Toxicol., 47, 1076-1079, 2009.

182. Gouveia-Figueira, S.C. and Castilho, P.C., Phenolic screening by HPLCDAD-ESI/MSn and antioxidant capacity of leaves, flowers and berries of Rubus grandifolius Lowe. Ind. Crop. Prod., 73, 28-40, 2015.

183. Zhang, Q.-A., Fan, X.-H., Zhang, Z.-Q., Li, T., Zhu, C.-P., Zhang, X.-R., and Song, W., Extraction, antioxidant capacity and identification of Semen Astragali Complanati (Astragalus complanatus R. Br.) phenolics. Food Chem., 141, 1295-1300, 2013.

184. Langer, S. and Lodge, J.K., Determination of selected water-soluble vitamins using hydrophilic chromatography: A comparison of photodiode array, fluorescence, and coulometric detection, and validation in a breakfast cereal matrix. J. Chromatogr. B, 960, 73-81, 2014.

185. Barros, L., Correia, D.M., Ferreira, I.C.F.R., Baptista, P., and Santos-Buelga, C., Optimization of the determination of tocopherols in Agaricus sp. edible mushrooms by a normal phase liquid chromatographic method. Food Chem., 110, 1046-1050, 2008.

186. Waksmundzka-Hajnos, M., Sherma, J., and Kowalska, T., Thin Layer Chromatography in Phytochemistry, CRC Press, 2008.

187. Simões-Pires, C.A., Hmicha, B., Marston, A., and Hostettmann, K., A TLC bioautographic method for the detection of $\alpha$ - and $\beta$-glucosidase inhibitors in plant extracts. Phytochem. Anal., 20, 511-515, 2009.

188. Willför, S., Eklund, P., Sjöholm, R., Reunanen, M., Sillanpää, R., von Schoultz, S., Hemming, J., Nisula, L., Holmbom, B.R., Bioactive phenolic substances in industrially important tree species. Part 4: Identification of two new 7-hydroxy divanillyl butyrolactol lignans in some spruce, fir, and pine species. Holzforschung, 59, 413-417, 2005.

189. Wang, M., Qu, F., Shan, X.-Q., and Lin, J.-M., Development and optimization of a method for the analysis of low-molecular-mass organic acids in plants by capillary electrophoresis with indirect UV detection. J. Chromatogr. A, 989, 285-292, 2003.

190. Pereira, C., Barros, L., Carvalho, A.M., and Ferreira, I.C.F.R., Use of UFLCPDA for the analysis of organic acids in thirty-five species of food and medicinal plants. Food Anal. Method., 6, 1337-1344, 2013. 
191. Barros, L., Pereira, C., and Ferreira, I.C.F.R., Optimized analysis of organic acids in edible mushrooms from Portugal by ultra fast liquid chromatography and photodiode array detection. Food Anal. Method., 6, 309-316, 2012.

192. Köhler, N., Wray, V., and Winterhalter, P., Preparative isolation of procyanidins from grape seed extracts by high-speed counter-current chromatography. J. Chromatogr. A, 1177, 114-125, 2008.

193. Rodríguez-Rivera, M.P., Lugo-Cervantes, E., Winterhalter, P., and Jerz, G., Metabolite profiling of polyphenols in peels of Citrus limetta Risso by combination of preparative high-speed countercurrent chromatography and LCESI-MS/MS. Food Chem., 158, 139-152, 2014.

194. Liu, D., Su, Z., Wang, C., Gu, M., and Xing, S., Separation and purification of hydrolyzable tannin from Geranium wilfordii Maxim by reversed-phase and normal-phase high-speed counter-current chromatagraphy. J. Sep. Sci., 33, 2266-2271, 2010.

195. Liang, J., Yang, Z., Cao, X., Wu, B., and Wu, S., Preparative isolation of novel antioxidant flavonoids of alfalfa by stop-and-go counter-current chromatography and following on-line liquid chromatography desalination. J. Chromatogr. A, 1218, 6191-6199, 2011.

196. Inoue, K., Baba, E., Hino, T., and Oka, H., A strategy for high-speed countercurrent chromatography purification of specific antioxidants from natural products based on on-line HPLC method with radical scavenging assay. Food Chem., 134, 2276-2282, 2012.

197. Watson, J.T. and Sparkman, O.D., Introduction to Mass Spectrometry: Instrumentation, Applications, and Strategies for Data Interpretation, John Wiley \& Sons, 2007.

198. Luna, L.C., Pigni, N.B., Torras-Claveria, L., Monferran, M.V., Maestri, D., D.A. Wunderlin, D.A., Feresin, G.E., Bastida, J., and Tapia, A., Ramorinoa girolae Speg (Fabaceae) seeds, an Argentinean traditional indigenous food: Nutrient composition and antioxidant activity. J. Food Comp. Anal., 31, 120-128, 2013.

199. Quifer-Rada, P., Vallverdú-Queralt, A., Martínez-Huélamo, M., ChivaBlanch, G., Jáuregui, O., Estruch, R., Lamuela-Raventós, R., A comprehensive characterisation of beer polyphenols by high resolution mass spectrometry (LC-ESI-LTQ-Orbitrap-MS). Food Chem., 169, 336-343, 2015.

200. Flamini, R., Mass spectrometry in grape and wine chemistry. Part I: Polyphenols. Mass Spectrom. Rev., 22, 218-250, 2003.

201. Bursal, E., Köksal, E., Gülçin, İ., and Bilsel, G., Antioxidant activity and polyphenol content of cherry stem (Cerasus avium L.) determined by LC-MS/ MS. Food Res. Int., 51, 66-74, 2013.

202. Plozza, T., Trenerry, V.C., and Caridi, D., The simultaneous determination of vitamins $\mathrm{A}, \mathrm{E}$ and $\beta$-carotene in bovine milk by high performance liquid chromatography-ion trap mass spectrometry (HPLC-MSn). Food Chem., 134, 559-563, 2012. 
203. Wong, Y.F., Makahleh, A., Saad, B., Ibrahim, M.N.M., Rahim, A.A., and Brosse, N., UPLC method for the determination of vitamin E homologues and derivatives in vegetable oils, margarines and supplement capsules using pentafluorophenyl column. Talanta, 130, 299-306, 2014.

204. Klimczak, I. and Gliszczyńska-Świgło, A., Comparison of UPLC and HPLC methods for determination of vitamin C. Food Chem., 175, 100-105, 2015.

205. Ortega, N., Romero, M.P., Macià, A., Reguant, J., Anglès, N., Morelló, J.R., Motilva, M.J., Comparative study of UPLC-MS/MS and HPLC-MS/MS to determine procyanidins and alkaloids in cocoa samples. J. Food Comp. Anal., 23, 298-305, 2010.

206. Prokudina, E.A., Havlíček, L., Al-Maharik, N., Lapčík, O., Strnad, M., and Gruz, J., Rapid UPLC-ESI-MS/MS method for the analysis of isoflavonoids and other phenylpropanoids. J. Food Comp. Anal., 26, 36-42, 2012.

207. Ho, C.S., Lam, C.W.K., Chan, M.H.M., Cheung, R.C.K., Law, L.K., Lit, L.C.W., Ng, K.F., Suen, M.W.M., and Tai, H.L., Electrospray ionisation mass spectrometry: Principles and clinical applications. Clin. Biochem. Rev., 24, 3-12, 2003.

208. Hejtmánková, K., Lachman, J., Hejtmánková, A., Pivec, V., and Janovská, D., Tocols of selected spring wheat (Triticum aestivum L.), einkorn wheat (Triticum monococcum L.) and wild emmer (Triticum dicoccum Schuebl [Schrank]) varieties. Food Chem., 123, 1267-1274, 2010.

209. Liu, Y.-R., Li, W.-G., Chen, L.-F., Xiao, B.-K., Yang, J.-Y., Yang, L., Zhang, C.-G., Huang, R.-Q., and Donga, J.-X., ABTS ${ }^{+}$scavenging potency of selected flavonols from Hypericum perforatum L. by HPLC-ESI/MS QQQ: Reaction observation, adduct characterization and scavenging activity determination. Food Res. Int., 58, 47-58, 2014.

210. Stalmach, A., Edwards, C.A., Wightman, J.D., and Crozier, A., Identification of (poly)phenolic compounds in concord grape juice and their metabolites in human plasma and urine after juice consumption. J. Agric. Food Chem., 59, 9512-9522, 2011.

211. Kazuma, K., Noda, N., and Suzuki, M., Malonylated flavonol glycosides from the petals of Clitoria ternatea. Phytochemistry, 62, 229-237, 2003.

212. Grotewold, E. (Ed.), The Science of Flavonoids, pp. 36-37, New York: Springer, 2006.

213. Francis, J.A., Rumbeiha, W., and Nair, M.G., Constituents in Easter lily flowers with medicinal activity. Life Sci., 76, 671-683, 2004.

214. Soininen, T.H., Jukarainen, N., Julkunen-Tiitto, R., Karjalainen, R., and Vepsäläinen, J.J., The combined use of constrained total-line-shape ${ }^{1} \mathrm{H}$ NMR and LC-MS/MS for quantitative analysis of bioactive components in yellow onion. J. Food Comp. Anal., 25, 208-214, 2012.

215. Otero, L. and Préstamo, G., Effects of pressure processing on strawberry studied by nuclear magnetic resonance. Innov. Food Sci. Emerg. Technol., 10, 434-440, 2009.

216. Kim, H.K., Choi, Y.H., and Verpoorte, R., NMR-based metabolomic analysis of plants. Nat. Protoc., 5, 536-549, 2010. 
217. Bino, R.J., Hall, R.D., Fiehn, O., Kopka, J., Saito, K., Draper, J., Nikolau, B.J., Mendes, P., Roessner-Tunali, U., Beale, M.H., Trethewey, R.N., Lange, B.M., Wurtele, E.S., Sumner, L.W., Potential of metabolomics as a functional genomics tool. Trends Plant Sci., 9, 418-425, 2004.

218. Frank, T., Engel, K.H., Weimer, B.C., and Slupsky, C., Metabolomic analysis of plants and crops, in: Metabolomics in Food and Nutrition, B.C. Weimer, C. Slupsky (Eds.), p. 148-191, Cambridge, UK: Woodhead Publishing Ltd, 2013.

219. Maltese, F., Erkelens, C., van der Kooy, F., Choi, Y.H., and Verpoorte, R., Quantification of main phenolic compounds in sweet and bitter orange peel using CE-MS/MS. Food Chem., 116, 575-579, 2009.

220. Chai, W., Shi, Y., Feng, H., Qiu, L., Zhou, H., Deng, Z., Yan, C., Chen, Q., NMR, HPLC-ESI-MS, and MALDI-TOF MS analysis of condensed tannins from Delonix regia (Bojer ex Hook.) Raf. and their bioactivities. J. Agric. Food Chem., 60, 5013-5022, 2012.

221. Lee, J.H., Lim, J.D., and Choung, M.G., Studies on the anthocyanin profile and biological properties from the fruits of Acanthopanax senticosus (Siberian Ginseng). J. Funct. Foods, 5, 380-388, 2013.

222. Jun, H.-I., Kim, B.T., Song, G.-S., and Kim, Y.-S., Structural characterization of phenolic antioxidants from purple perilla (Perilla frutescens var. acuta) leaves. Food Chem., 148, 367-372, 2014.

223. Wang, W., Guo, J., Zhang, J., Peng, J., Liu, T., and Xin, Z., Isolation, identification and antioxidant activity of bound phenolic compounds present in rice bran. Food Chem., 171, 40-49, 2015.

224. Chen, J.-Y., Xu, Y.-J., Ge, Z.-Z., Zhu, W., Xu, Z., and Li, C.-M., Structural elucidation and antioxidant activity evaluation of key phenolic compounds isolated from longan (Dimocarpus longan Lour.) seeds. J. Funct. Foods, 17, 872-880, 2015.

225. Cen, H. and He, Y., Trends Food Sci. Technol., Theory and application of near infrared reflectance spectroscopy in determination of food quality. 18, 72-83, 2007.

226. Atienza, S.G., Avila, C.M., Ramirez, M.C., and Martin, A., Application of near infrared reflectance spectroscopy to the determination of carotenoid content in tritordeum for breeding purposes. Crop Pasture Sci., 56, 85-89, 2005.

227. Pedro, A.M., and Ferreira, M.M., Nondestructive determination of solids and carotenoids in tomato products by near-infrared spectroscopy and multivariate calibration. Anal. Chem., 77, 2505-2511, 2005.

228. Chen, X., Wu, J., Zhou, S., Yang, Y., Ni, X., Yang, J., Zhu, Z., Shi, C., Application of near-infrared reflectance spectroscopy to evaluate the lutein and $\beta$-carotene in Chinese kale. J. Food Comp. Anal., 22, 148-153, 2009.

229. Cozzolino, D., Cynkar, W.U., Dambergs, R.G., Mercurio, M.D., and Smith, P.A., Measurement of condensed tannins and dry matter in red grape homogenates using near infrared spectroscopy and partial least squares. J. Agric. Food Chem., 56, 7631-7636, 2008. 
230. Wu, Q., Qu, H., Jia, J., Kuang, C., Wen, Y., Yan, H., and Gui, Z., Characterization, antioxidant and antitumor activities of polysaccharides from purple sweet potato. Carbohydr. Polym., 132, 31-40, 2015.

231. Pissard, A., Fernández Pierna, J.A., Baeten, V., Sinnaeve, G., Lognay, G., A. Mouteau, A., Dupont, P., Rondia, A., and Lateur, M., Non-destructive measurement of vitamin $\mathrm{C}$, total polyphenol and sugar content in apples using near-infrared spectroscopy. J. Sci. Food Agr., 93, 238-244, 2013.

232. Blanco-Díaz, M.T., Del Río-Celestino, M., Martínez-Valdivieso, D., and Font, R., Use of visible and near-infrared spectroscopy for predicting antioxidant compounds in summer squash (Cucurbita pepo ssp pepo). Food Chem., 164, 301-308, 2014.

233. Mushtaq, M., Gani, A., Shetty, P.H., Masoodi, F.A., and Ahmad, M., Himalayan cheese (Kalari/kradi): Effect of different storage temperatures on its physicochemical, microbiological and antioxidant properties. LWT-Food Sci. Technol., 63, 837-845, 2015.

234. Lim, S.J., Aida, W.M.W., Maskata, M.Y., Mamota, S., Ropien, J., and Mohd, D.M., Isolation and antioxidant capacity of fucoidan from selected Malaysian seaweeds. Food Hydrocoll., 42, 280-288, 2014. 